\title{
G9a/GLP Histone Lysine Dimethyltransferase Complex Activity in the Hippocampus and the Entorhinal Cortex Is Required for Gene Activation and Silencing during Memory Consolidation
}

\author{
Swati Gupta-Agarwal, ${ }^{1}$ Aimee V. Franklin, ${ }^{2}$ Thomas DeRamus, ${ }^{1}$ Muriah Wheelock, ${ }^{3}$ Robin L. Davis, ${ }^{3}$ Lori L. McMahon, ${ }^{2}$ \\ and Farah D. Lubin ${ }^{1}$ \\ ${ }^{1}$ The Evelyn F. McKnight Brain Institute, Department of Neurobiology, and Departments of ${ }^{2}$ Physiology and ${ }^{3}$ Psychology and Behavioral Neuroscience, \\ University of Alabama at Birmingham, Birmingham, Alabama 35294
}

Learning triggers alterations in gene transcription in brain regions such as the hippocampus and the entorhinal cortex (EC) that are necessary for long-term memory (LTM) formation. Here, we identify an essential role for the G9a/G9a-like protein (GLP) lysine dimethyltransferase complex and the histone $\mathrm{H} 3$ lysine 9 dimethylation ( $\mathrm{H} 3 \mathrm{~K} 9 \mathrm{me} 2)$ marks it catalyzes, in the transcriptional regulation of genes in area CA1 of the rat hippocampus and the EC during memory consolidation. Contextual fear learning increased global levels of H3K9me2 in area CA1 and the EC, with observable changes at the Zif268, DNMT3a, BDNF exon IV, and cFOS gene promoters, which occurred in concert with mRNA expression. Inhibition of G9a/GLP in the EC, but not in the hippocampus, enhanced contextual fear conditioning relative to control animals. The inhibition of G9a/GLP in the EC induced several histone modifications that include not only methylation but also acetylation. Surprisingly, we found that downregulation of G9a/GLP activity in the EC enhanced H3K9me2 in area CA1, resulting in transcriptional silencing of the non-memory permissive gene COMT in the hippocampus. In addition, synaptic plasticity studies at two distinct EC-CA1 cellular pathways revealed that G9a/GLP activity is critical for hippocampus-dependent long-term potentiation initiated in the EC via the perforant pathway, but not the temporoammonic pathway. Together, these data demonstrate that G9a/GLP differentially regulates gene transcription in the hippocampus and the EC during memory consolidation. Furthermore, these findings support the possibility of a role for G9a/GLP in the regulation of cellular and molecular cross talk between these two brain regions during LTM formation.

\section{Introduction}

Learning triggers several molecular events in the CNS that are necessary for long-term memory (LTM) formation. In this regard, multiple intracellular signaling cascades and transcription factors have been identified as crucial for gene expression changes during memory consolidation; however, these molecular events are transient in nature and do not adequately support the persistent effects of gene transcription on LTM. Thus, an emerging research idea is that chromatin remodeling via epigenetic modifications may serve as a candidate mechanism for persistent regulation of gene activity required for the maintenance and storage

\footnotetext{
Received Jan. 10, 2012; revised Feb. 20, 2012; accepted Feb. 25, 2012.

Author contributions: L.L.M. and F.D.L. designed research;S.G.-A., A.V.F., T.D., M.W., R.L.D., and F.D.L. performed research; S.G.-A., A.V.F., and F.D.L. analyzed data; S.G.-A. and F.D.L. wrote the paper.

This work was supported by the National Institute of Mental Health (Grant MH082106 to F.D.L.), the Federation of American Societies for Experimental Biology (F.D.L.), National Institute of General Medical Sciences Training Grant T32 GM008111 to S.G., and the Evelyn F. McKnight Brain Research Foundation. We thank Rosemary Puckett for editorial comments, Drs. Lynn Dobrunz and Brandon Walters for valuable comments on electrophysiology experiments, and Dr. Jianbo Wang and Tanvi Sinha for technical advice with the confocal imaging.

Correspondence should be addressed to Dr. Farah D. Lubin, Department of Neurobiology, University of Alabama at Birmingham, 1825 University Boulevard, Birmingham, AL 35294. E-mail: flubin@nrc.uab.edu.

DOI:10.1523/JNEUROSCI.0147-12.2012

Copyright $\odot 2012$ the authors $\quad 0270-6474 / 12 / 325440-14 \$ 15.00 / 0$
}

of LTM (Levenson et al., 2004; Lubin et al., 2008, 2011; Gupta et al., 2010).

Data obtained from learning and memory animal models have indicated that epigenetic mechanisms, including DNA methylation and histone acetylation, occur in postmitotic neurons without altering the DNA sequence (Levenson et al., 2004; Tsankova et al., 2006; Fischer et al., 2007; Vecsey et al., 2007; Lubin et al., 2008; Miller et al., 2008; Guan et al., 2009; Koshibu et al., 2009; Barrett, 2011; Haettig et al., 2011; Hawk et al., 2011; Malvaez et al., 2011; McQuown et al., 2011; Oliveira et al., 2011). Histone lysine methylation (HKM) is another epigenetic mechanism that is typically associated with persistent chromatin remodeling and is therefore a powerful controller of gene transcription. Indeed, previous research in the CNS has inspired investigations into HKM mechanisms in the adult brain subserving synaptic plasticity and memory formation (Akbarian and Huang, 2009; Gupta et al., 2010).

Histone $\mathrm{H} 3$ lysine 9 dimethylation ( $\mathrm{H} 3 \mathrm{~K} 9 \mathrm{me} 2)$ is a prominent HKM modification controlled by the G9a/G9a-like protein (GLP) complex and has been implicated in diverse processes, including transcriptional silencing, heterochromatin formation, and DNA methylation (Rea et al., 2000; Sims et al., 2003; 
Margueron et al., 2005; Martin and Zhang, 2005; Vermeulen et al., 2007; Shinkai and Tachibana, 2011). Investigation of postnatal forebrain knockdown of G9a/GLP revealed a close resemblance to a mental retardation syndrome caused by subtelomeric deletion of the human chromosome 9 (9q34) (Schaefer et al., 2009). In fact, a growing literature suggests that G9a/GLP activity may play a role in several behaviors, including drug addiction (Maze et al., 2010; Covington et al., 2011). Furthermore, the idea that LTM storage requires not only positive regulation of gene expression but negative gene regulation as well has been essentially unexplored.

Here, we examine a role for G9a/GLP-mediated transcriptional silencing in the hippocampus and the entorhinal cortex (EC) during memory consolidation. We found that $\mathrm{H} 3 \mathrm{~K} 9 \mathrm{me} 2$ is regulated in the hippocampus and the EC during memory consolidation and that inhibition of G9a/GLP in the EC, but not the hippocampus, results in the enhancement of LTM formation. We also found that G9a/GLP blockade in the EC altered H3K9me2 regulation in area $\mathrm{CA} 1$, indicating the possibility of a role for G9a/GLP in mediating cellular and molecular connectivity between these two brain regions during memory consolidation. We further demonstrate that the behavioral effects of G9a/GLP inhibition in the hippocampus and the EC were reflected at the cellular synaptic plasticity level. Together, these findings support an important role for G9a/GLP epigenetic activity in the hippocampus and the EC that is necessary for LTM.

\section{Materials and Methods}

\section{Animals}

Adult male Sprague Dawley rats $(250-300 \mathrm{~g})$ were used for all experiments.

Animals were housed under $12 \mathrm{~h}$ light/dark conditions and allowed access to rodent chow and water ad libitum. Animals acclimatized to laboratory conditions and were handled at least $3 \mathrm{~d}$ before use. All procedures were performed with the approval of the University of Alabama at Birmingham Institutional Animal Care and Use Committee and according to national guidelines and policies.

\section{Behavioral procedures}

Animals were transported $2 \mathrm{~h}$ before fear conditioning on experiment day.

Contextual fear-conditioning protocol. The animals were placed in a chamber and allowed to explore for $2 \mathrm{~min}$, followed immediately by a $1 \mathrm{~s}$, $0.5 \mathrm{~mA}$ subthreshold footshock. This $2 \mathrm{~min}, 1 \mathrm{~s}$ pairing was repeated three times over the course of $6 \mathrm{~min}$, ending with an additional $1 \mathrm{~min}$ exploratory period before removal of the animal from the chamber. The context-alone animals were placed in the same chamber for a total of 7 min with no footshocks. Naive-alone animals were left untouched in their cages in the same room. For behavioral experiments, animals were re-placed in the same chamber $24 \mathrm{~h}$ later, and freezing behavior was monitored for a period of $5 \mathrm{~min}$.

Cued fear-conditioning protocol. The animals were placed in chamber A and allowed to explore for $50 \mathrm{~s}$, followed by a $90 \mathrm{~dB}, 500 \mathrm{~Hz}$ tone for $20 \mathrm{~s}$ coterminating with a $2 \mathrm{~s}, 0.5 \mathrm{~mA}$ subthreshold footshock. The $2 \mathrm{~s}, 0.5 \mathrm{~mA}$ cue-shock pairing was repeated three times over the duration of $6 \mathrm{~min}$. Twenty-four hours later, animals were placed in a novel chamber B, and freezing behavior was measured in response to the $90 \mathrm{~dB}, 500 \mathrm{~Hz}$ tone in the absence of a footshock.

Extinction. Animals were subject to contextual fear conditioning as described above and tested for freezing behavior during reexposure to the context in the absence of the footshock for $5 \mathrm{~d}$ consecutively.

\section{Cannulae implantation}

Animals were bilaterally placed with a 31 gauge single-guide cannula or a 23 gauge double-guide cannula, from which the injector projected $1 \mathrm{~mm}$ to the end in the intradorsolateral entorhinal cortex and intra-area CA1 of the hippocampus, respectively. The stereotaxic coordinates used for intra-EC surgeries were as follows: AP, $-6.8 \mathrm{~mm}$ from bregma; $\mathrm{ML}, \pm 5.0$ $\mathrm{mm}$; DV,$-8.1 \mathrm{~mm}$ from skull; coordinates for intra-area CA1 of the hippocampus were as follows: AP, $-3.6 \mathrm{~mm}$ from bregma, $\mathrm{ML}, \pm 1.7$ $\mathrm{mm}$; DV , $-2.6 \mathrm{~mm}$ from skull (Paxinos et al., 1980). Cresyl violet staining was performed to confirm cannula placement. Animals were habituated to dummy cannula removal and allowed to recover for $5 \mathrm{~d}$ before infusion and behavioral studies.

\section{Drug}

Animals were infused with either saline $(0.9 \% \mathrm{NaCl}, \mathrm{pH} 7.4)$ or BIX01294 (concentration, $45 \mu \mathrm{M}$; Sigma-Aldrich) or UNC0224 (concentration, $15 \mathrm{~nm}$; Sigma-Aldrich) $1 \mathrm{~h}$ before fear conditioning.

\section{Isolation of area CA1 and EC}

Whole brain was removed and placed in oxygenated $\left(95 \% / 5 \% \mathrm{O}_{2} / \mathrm{CO}_{2}\right)$, ice-cold cutting solution (in mm: 110 sucrose, $60 \mathrm{NaCl}, 3 \mathrm{KCl}, 1.25$ $\mathrm{NaH}_{2} \mathrm{PO}_{4}, 28 \mathrm{NaHCO}_{3}, 0.5 \mathrm{CaCl}_{2}, 7 \mathrm{mM} \mathrm{MgCl}_{2}, 5$ glucose, and 0.6 ascorbate). Area $\mathrm{CA} 1$ of the hippocampus and $\mathrm{EC}$ were microdissected and flash frozen on dry ice. All isolated tissue was stored at $-80^{\circ} \mathrm{C}$ for future processing.

\section{Immunohistochemistry}

Whole brains were removed and flash frozen in tissue-freezing medium O.C.T. (optimal cutting temperature). Eight-micrometer sections taken on the cryostat were collected on Fisherbrand colorfrost/plus slides. A total of $4 \%$ paraformaldehyde was used to fix sections, followed by citrate buffer treatment for antigen retrieval. There was a $24 \mathrm{~h}$ incubation with blocking buffer ( $10 \%$ normal goat serum) at $4^{\circ} \mathrm{C}$, followed by primary antibody treatment (H3K9me2, catalog \#07-441, 1:100, Millipore; H3K4me3, catalog \#04-745, 1:100, Millipore) or no antibody control for $48 \mathrm{~h}$ at $4^{\circ} \mathrm{C}$. Sections were subjected to PBS-Tween washes, followed by secondary antibody [DyLight 488 AffiniPure Goat Anti-Mouse IgG $(\mathrm{H}+\mathrm{L})$ at $1: 500$ ] treatment for $1 \mathrm{~h}$ at room temperature. PBS-Tween washes were followed by mounting using the VectaSheild Mounting Medium Hardset with DAPI. Images $(20 \times)$ were taken on the Zeiss AxioImager microscope, and $180 \times$ confocal images were taken on the Olympus FV1000 confocal microscope. ImageJ software was used for all quantifications. All EC and area CA1 analyses were restricted to bregma limits -5.64 to $-6.72 \mathrm{~mm}$ and -2.96 to $-3.72 \mathrm{~mm}$, respectively.

\section{Microarray}

Area CA1 of the hippocampus was isolated from fear-conditioned and naive control animals and provided to Almacs Diagnostic Center for microarray analysis. RNA was extracted and amplified using the NuGEN protocol followed by the GeneChip Expression Analysis program (Affymetrix). The output file contained the raw signals of the test and reference samples and the $\log _{2}$ ratio representing the fold differences between the test and reference samples. The analysis program gives a present/ absent call for each spot on the array based on a predetermined signalto-noise ratio, along with a not changed (NC)/increase/marginal increase (MI)/decrease/marginal decrease (MD) call for the two-array comparison. The genes that had an NC/MI/MD call were filtered out.

\section{Histone extraction}

Histone extraction was performed as described previously (Lubin and Sweatt, 2007; Lubin et al., 2008; Gupta et al., 2010). Briefly, homogenized tissue was subjected to centrifugation at $7700 \times g$ for $1 \mathrm{~min}$. Nuclei pellets were resuspended in $250 \mu \mathrm{l}$ of $0.4 \mathrm{~N} \mathrm{H}_{2} \mathrm{SO}_{4}$, incubated on ice for $30 \mathrm{~min}$, and centrifuged at $4^{\circ} \mathrm{C}$ for $30 \mathrm{~min}$ at $14,000 \times g$. Protein was precipitated and recovered by centrifugation, followed by acetone drying. All procedures were performed under ice-cold conditions. The purified histoneenriched protein pellet was resuspended in $10 \mathrm{~mm}$ Tris, $\mathrm{pH}$ 8.0. Protein concentrations were determined via the Bio-Rad protein assay reagent.

\section{Western blotting}

For quantification of HKM and acetylation levels, histone protein extracts $(1 \mu \mathrm{g})$ were separated on a $12 \%$ polyacrylamide gel with a $4 \%$ stacking gel. The histone proteins were transferred onto an Immobilon-FL membrane, which was then probed with the following primary antibodies: H3K9me2 (1:500), H3K4me3 (1:500), H3K9ac (catalog \#06-942, 1:1000; Millipore), and TH3 (catalog \#Ab10799, 1:1000; Abcam). Secondary goat anti-rabbit $800 \mathrm{CW}$ antibody was used for de- 
tection of histone protein using the Licor Odyssey system. All quantifications were normalized to total histone $\mathrm{H} 3$ levels.

Measuring $m R N A$ levels by real-time reverse transcriptase-PCR Isolated area CA1 of the hippocampus and EC was subjected to RNA extraction using the All Prep DNA/RNA mini kit (catalog \#80204; QIAGEN). RNA was converted to cDNA using the iScript cDNA synthesis kit (Bio-Rad). All cDNA samples were preamplified at $95.0^{\circ} \mathrm{C}$ for $10 \mathrm{~min}, 20$ repeats of $95.0^{\circ} \mathrm{C}$ for $15 \mathrm{~s}, 60.0^{\circ} \mathrm{C}$ for $1 \mathrm{~min}$, and, finally, hold at $4.0^{\circ} \mathrm{C}$. reverse transcriptase (RT)-PCR amplifications were performed on the iQ5 real-time PCR system (Bio-Rad) at $95.0^{\circ} \mathrm{C}$ for $3 \mathrm{~min}, 50$ repeats of $95.0^{\circ} \mathrm{C}$ for $10 \mathrm{~s}$, followed by $62.6^{\circ} \mathrm{C}$ for $30 \mathrm{~s}, 95.0^{\circ} \mathrm{C}$ for $1 \mathrm{~min}, 55.0^{\circ} \mathrm{C}$ for $1 \mathrm{~min}, 81$ repeats of $55.0^{\circ} \mathrm{C}$ for $10 \mathrm{~s}$ each, and, finally, hold at $4.0^{\circ} \mathrm{C}$, using primer sets specific to regions of interest in the $c F O S$ (forward, CCCGTAGA CCTAGGGAGGAC; reverse, CAATACACTCCATGCGGTTG), Zif268 (forward, TCAGCCTAGTCAGTGGCCTT; reverse, AGGTCTCCCTGT TGTTGTGG), DNMT3a (forward, ACGCCAAAGAAGTGTCTGCT; reverse, CTTTGCCCTGCTTTATGGAG), brain-derived neurotrophic factor exon IV (BDNF exon IV; forward, TGCGAGTATTACCTCCGCCA T; reverse, TCACGTGCTCAAAAGTGTCAG), G9a (forward, CCCAGA GGAGTGAATGGTGT; reverse, CTTTCGGTGGCCATACACTT), and catechol-O-methyltransferase (COMT; forward, CCCTCCTGTCGGAT TACTCA; reverse, GGGGGAAGCACATGAGTCTA) gene promoters. Quantification of $\beta$-tubulin-4 levels were used as an internal control for normalization. All PCR product sizes were confirmed by electrophoresing on a $2 \%$ agarose gel and visualizing using ethidium bromide.

\section{Chromatin immunoprecipitation}

Chromatin immunoprecipitation (ChIP) assays were performed as described previously. Briefly, microdissected tissue was held in ice-cold PBS solution containing protease inhibitors. The protein was cross-linked using $1 \%$ formaldehyde in $\mathrm{PBS}$ at $37^{\circ} \mathrm{C}$ for $10 \mathrm{~min}$, followed by washes with ice-cold PBS containing protease inhibitors. Tissue homogenization was performed in SDS lysis buffer (in mM: 50 Tris, pH 8.1, 10 EDTA, 1\% SDS) and subjected to shearing using a Branson sonifier 250 at 1.5 power and constant duty cycle. Extracts were precleared with $50 \%$ suspension of salmon sperm-saturated protein A overnight. Immunoprecipitations were performed overnight at $4^{\circ} \mathrm{C}$ with primary antibodies ( $\mathrm{H} 3 \mathrm{~K} 9 \mathrm{me} 2$, $\mathrm{H} 3 \mathrm{~K} 4 \mathrm{me} 3$ ) or no antibody (control). Immune complexes were recovered with protein A, followed up by consecutive washes with low-salt buffer, high-salt buffer, LiCl immune complex buffer, and Tris-EDTA (TE) buffer. The immunocomplex was extracted in $1 \times \mathrm{TE}$ buffer, and the protein-DNA cross-link was reverted by overnight treatment at $65^{\circ} \mathrm{C}$. The samples were subjected to proteinase K digestion $(100 \mu \mathrm{g} ; 2 \mathrm{~h}$ at $37^{\circ} \mathrm{C}$ ), and DNA extraction was via phenol/chloroform/isoamyl alcohol and precipitation using ethanol. All DNA samples were preamplified at $95.0^{\circ} \mathrm{C}$ for $10 \mathrm{~min}, 20$ repeats of $95.0^{\circ} \mathrm{C}$ for $15 \mathrm{~s}$ and $60.0^{\circ} \mathrm{C}$ for $1 \mathrm{~min}$, and hold at $4.0^{\circ} \mathrm{C}$. Quantitative RT-PCR was performed on the immunoprecipitated DNA using primers specific to Zif268 (forward, ATGGGCTG TTAGGGACAGTG; reverse, CCACTGAGCTAAATCCCCAA), cFOS (forward,GAAGGCAGAACCCTTTGATG;reverse, GCATAGAAGGAACC GGACAG), DNMT3a (forward, ACGCCAAAGAAGTGTCTGCT; reverse, CTTTGCCCTGCTTTATGGAG), BDNF exon IV (forward, ATGCAATG CCCTGGAACGGAA; reverse, TAGTGGAAATTGCATGGCGGAGGT), and COMT (forward, TAGTGGAAATTGCATGGCGGAGGT; reverse, AC AGGTCCGATCCCGACGCT) gene promoters. All amplicon quantifications were normalized to input DNA.

\section{Slice preparation and electrophysiology}

Hippocampal slices $(400 \mu \mathrm{m})$ were prepared from 6- to 8-week-old Sprague Dawley rats. Rats were anesthetized using inhalation (isoflurane) and rapidly decapitated. Brains were placed in "high sucrose" icecold artificial CSF (ACSF) containing (in $\mathrm{mm}$ ) $85 \mathrm{NaCl}, 2.5 \mathrm{KCl}, 0.5$ $\mathrm{CaCl}_{2}, 4 \mathrm{MgSO}_{4}, 1.25 \mathrm{NaH}_{2} \mathrm{PO}_{4}, 25 \mathrm{NaHCO}_{3}, 25$ glucose, and 75 sucrose saturated with $95 \% \mathrm{O}_{2}-5 \% \mathrm{CO}_{2}$. Coronal slices were cut using a vibratome (Vibratome). Prepared slices were transferred to standard ACSF containing (in mM) $119 \mathrm{NaCl}, 2.5 \mathrm{KCl}, 2.5 \mathrm{CaCl}_{2}, 1.3 \mathrm{MgSO}_{4}, 1$ $\mathrm{NaH}_{2} \mathrm{PO}_{4}, 26 \mathrm{NaHCO}_{3}$, and 10 glucose, saturated with $95 \% \mathrm{O}_{2}-5 \% \mathrm{CO}_{2}$. For recording, slices were placed in a submersion chamber and perfused with standard ACSF warmed to $28-30^{\circ} \mathrm{C}$. Late phase long-term potenti- ation (L-LTP) experiments were performed in acutely prepared hippocampal slices. For recording, slices were placed in a submersion chamber and continuously perfused with standard ACSF or ACSF containing BIX01294 $(1 \mu \mathrm{M})$. A bipolar stimulating electrode (FHC) was placed in stratum radiatum of hippocampus to stimulate Schaffer collaterals. Extracellular excitatory dendritic field potentials (fEPSPs) were recorded (Axoclamp 2B; Molecular Devices). A 20 min baseline was acquired using $0.2 \mathrm{~Hz}(100 \mu$ s duration) stimulation frequency. After acquisition of baseline, L-LTP was elicited by delivering four trains of 100 pulses at $100 \mathrm{~Hz}, 60$ s apart (HFS).

\section{Statistical analysis}

Comparison between the immunohistochemical results, Western blotting results, and ChIP analysis between the groups of animals was done using one-way ANOVA with Tukey's or Bartlett's post hoc test or one sample $t$ test or Student's $t$ test. Behavioral characterization of the salineversus drug-infused animal was done using Student's $t$ test. Extinction behavior was analyzed using two-way ANOVA, and line regression analysis was done to determine the rate of extinction. All electrophysiology data were expressed as mean \pm SEM. Comparison of data from different treatment groups was performed using the two-tailed Student's $t$ test, and baseline analysis was performed by the paired Student's $t$ test. Electrophysiology data were filtered at $3 \mathrm{kHz}$, digitized at $10 \mathrm{kHz}$, and acquired using LabVIEW data acquisition software (Richard Mooney, Duke University, Durham, NC). The magnitude of L-LTP was determined by taking the slopes of the rising phase of the fEPSPs and was normalized to baseline.

\section{Results}

\section{Activation and silencing of gene transcripts in the} hippocampus during contextual fear memory consolidation

To establish that both transcriptional activation and silencing of genes occur during LTM formation, we assessed the expression profile of genes in adult male rats $1 \mathrm{~h}$ after contextual conditioned fear (CCF) using microarray analysis. The CCF training paradigm involves the pairing of a novel context (conditioned stimulus) with a mild footshock (unconditioned stimulus) (Fanselow, 2000). A 1.5-fold cutoff threshold revealed significant upregulation of genes (1523) and downregulation of genes (1508) in area CA1 of the hippocampus after CCF (Fig. 1A). Furthermore, we identified a subset of 507 genes that were either directly or indirectly implicated in epigenetic mechanisms (epigenetically related genes), of which 239 were upregulated and 268 were downregulated in area CA1 (Fig. 1A, Table 1). These data strengthen the concept that learning triggers a balance between the activation and silencing of genes in the hippocampus during memory consolidation.

Since HKM can serve to regulate both activation and silencing of genes, we determined whether histone $\mathrm{H} 3$ lysine methylation regulation occurred in the hippocampus during CCF memory consolidation using immunohistochemistry analysis. Animals were divided into three groups: naive controls, context exposure alone (Context), and the CCF-trained group that received the context-plus-shock pairing (Trained). At $1 \mathrm{~h}$ after CCF training, $20 \times$ images of the pyramidal cell layer in area CA1 and $180 \times$ confocal images of single cells were acquired to quantify total nuclear integrated intensity levels. We observed significant increases in $\mathrm{H} 3 \mathrm{~K} 9 \mathrm{me} 2$ intensity levels in area CA1 neurons with context exposure alone (Fig. $1 B$ ). Furthermore, significant increases in both $\mathrm{H} 3 \mathrm{~K} 9 \mathrm{me} 2$ and histone $\mathrm{H} 3$ lysine 4 trimethylation (H3K4me3) intensity levels were observed in area CA1 neurons after CCF training compared with naive controls (Fig. $1 B$ ). These results strongly suggest that HKM changes in the hippocampus are triggered by CCF learning and are in agreement with previous reports (Gupta et al., 2010). 

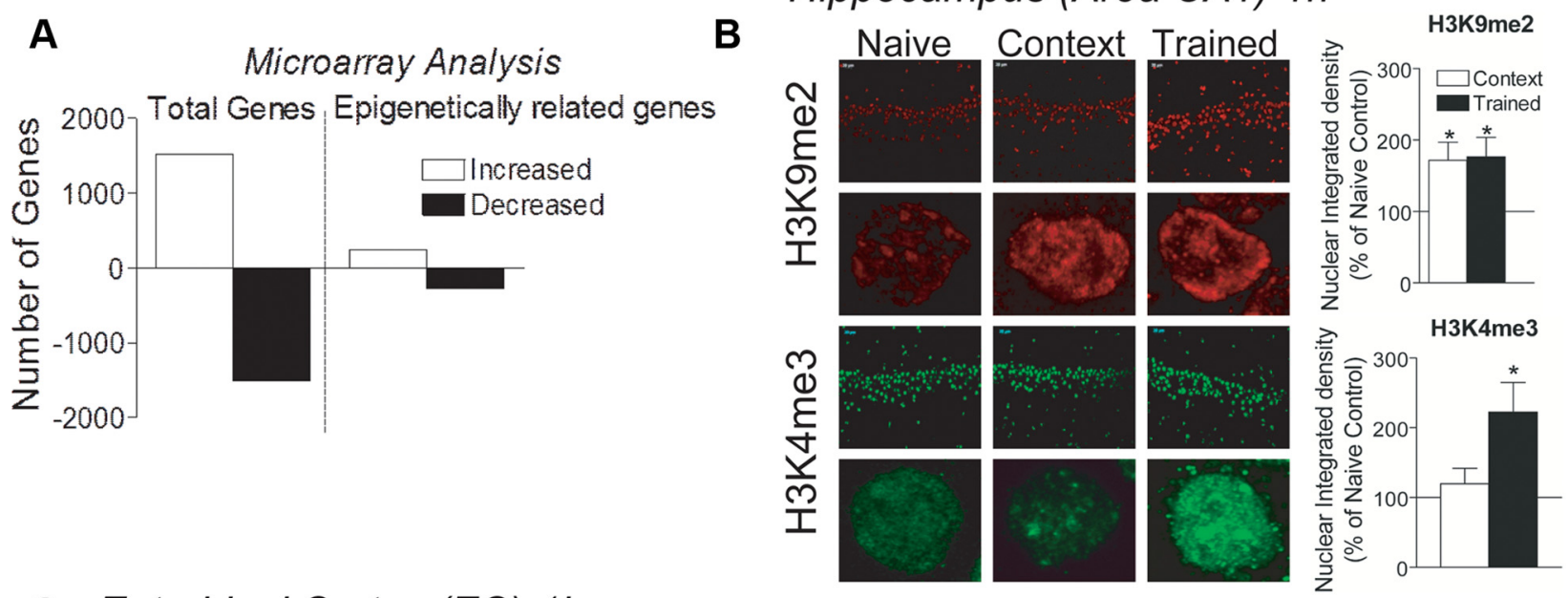

\section{Entorhinal Cortex (EC)-1h}
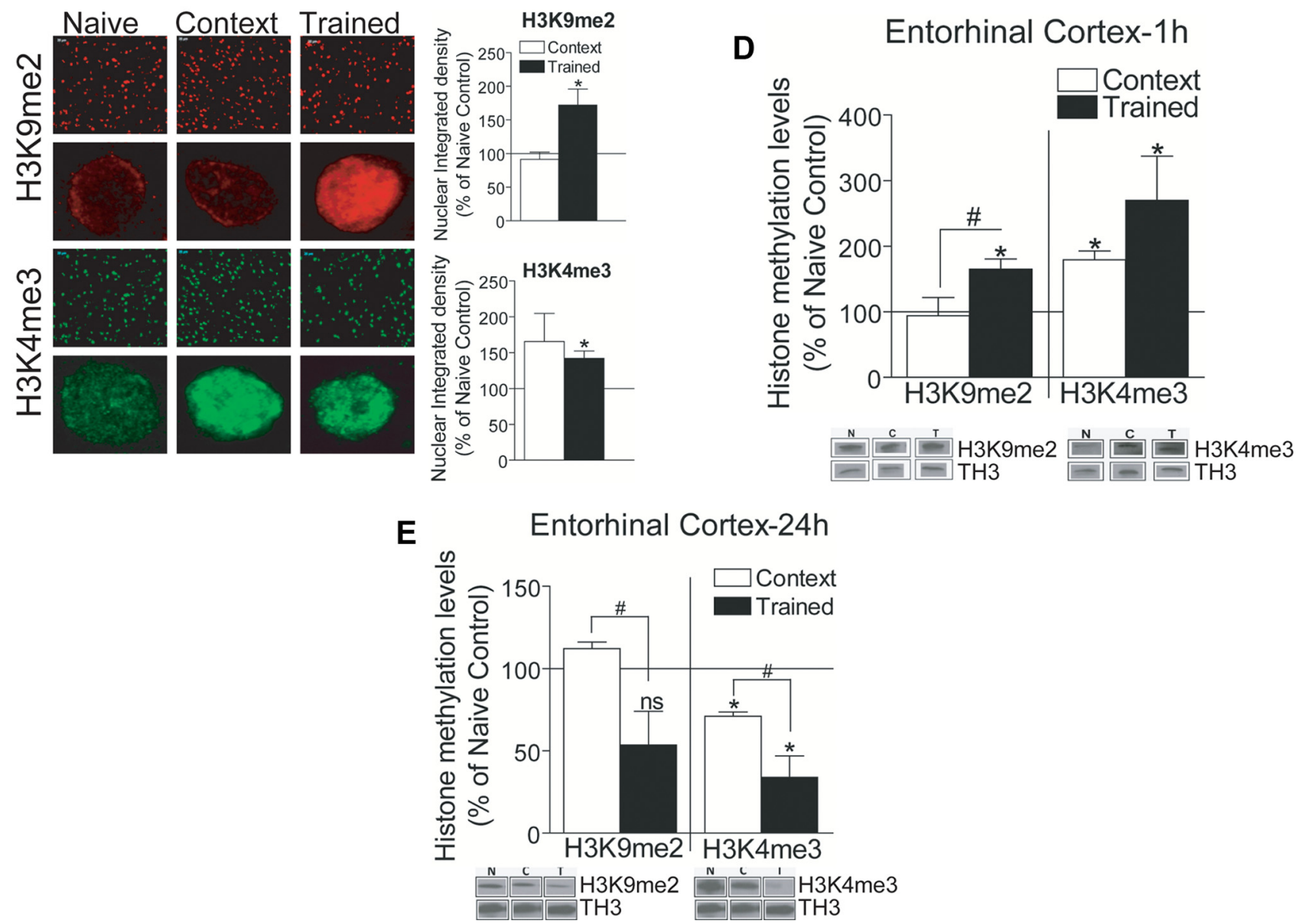

Figure 1. Histone lysine methylation regulation in the hippocampus and the EC after fear conditioning. $\boldsymbol{A}$, Using a 1.5-fold threshold cutoff, Affymetrix microarray analysis show differential regulation of genes in area CA1 of the hippocampus during fear memory consolidation, of which a subset of epigenetically linked were identified using a onefold threshold cutoff ( $n=3$ ). $\boldsymbol{B}$, Representative $20 \times$ and $180 \times$ confocal images of H3K9me2 (red) revealed significant increases in area $\left(A 1\right.$ of the hippocampus after context exposure alone (Context; $\left.t_{(4)}=2.816 ; p<0.05\right)$ and contextual conditioned fear (Trained; $t_{(4)}=2.84 ; p<0.05$ ) compared with naive controls. At $1 \mathrm{~h}$ after contextual conditioned fear, H3K4me3 levels ( $\mathrm{green}$ ) were significantly increased in area CA1 (Trained; $t_{(4)}=2.881 ; p<0.05 ; n=5$ ) compared with naive controls. C, Representative $20 \times$ and $180 \times$ confocal images of H3K9me2 (red) revealed significant increases in the EC at $1 \mathrm{~h}$ after contextual conditioned fear (Trained; $t_{(4)}=2.998 ; p<0.05$ ) compared with naive controls. Confocal images show increases in H3K4me3 (green) integrated density levels in the EC at $1 \mathrm{~h}$ after contextual conditioned fear compared with naive controls $\left(t_{(4)}=4.118 ; p<0.05 ; n=4-5\right)$. A trend toward an increase in H3K4me3 integrated density levels in the $\mathrm{EC}$ of context exposure alone (Context; $t_{(3)}=1.674 ; p=0.1927 ; n=3-4$ ) to naive controls. $D$, Western blotting analysis show increases in $\mathrm{H} 3 \mathrm{~K} 9 \mathrm{me} 2$ levels in the $\mathrm{EC}$ at $1 \mathrm{~h}$ after contextual conditioned fear (Trained; $t_{(7)}=$ $4.176 ; p<0.05 ; n=3-9$ ) and context exposure alone (Context; $t_{(11)}=2.427 ; p<0.05 ; n=3-9$ ) compared with naive controls. At $1 \mathrm{~h}$, H3K4me3 levels were increased in the EC after both context exposure alone (Context; $t_{(2)}=5.970 ; p<0.05 ; n=3$ ) and contextual conditioned fear (Trained; $\left.t_{(7)}=2.51 ; p<0.05 ; n=4-5\right)$ compared with naive controls. $\boldsymbol{E}$, At $24 \mathrm{~h}$, H3K9me2 levels returned to basal levels in the $\mathrm{EC}$ after both context exposure (Context) and contextual conditioned fear (Trained). At $24 \mathrm{~h}$, H3K4me3 levels were significantly decreased in the EC of context exposure alone (Context; $t_{(3)}=11.22 ; p<0.05$ ) and contextual conditioned fear (Trained; $\left.t_{(4)}=5.077 ; p<0.05\right)$ compared with naive controls $(n=4-5)$. Error bars are SEM; solid lines represent normalized naive control levels. *Significance relative to naive control group; " significance between experimental groups. 
Table 1. List of epigenetically related genes identified in the hippocampus of fear-conditioned animals

\begin{tabular}{|c|c|c|c|c|c|}
\hline $\begin{array}{l}\text { Serial } \\
\text { number }\end{array}$ & Gene name & Gene symbol & $\begin{array}{l}\text { Accession } \\
\text { number }\end{array}$ & $\begin{array}{l}\text { Fold } \\
\text { change }\end{array}$ & Function \\
\hline 1 & Calcineurin B, type II & Ppp3r2 & NM_021701 & -2.3 & $\begin{array}{l}\text { Protein phosphatase that negatively regulates memory formation (Man- } \\
\text { suy, 2003) }\end{array}$ \\
\hline 2 & Dicer 1, Dcr-1 homolog (Drosophila) & Dicer 1 & Al406925 & -1.1 & Ribonuclease required for RNA interference \\
\hline 3 & Protein phosphatase 2 & Ppp2r2c & NM_057116 & -1.7 & $\begin{array}{l}\text { Protein phosphatase implicated in Alzheimer's disease resulting in tau } \\
\text { hyperphosphorylation (Sun et al., 2003) }\end{array}$ \\
\hline 4 & Protein phosphatase 1 & Ppp1r3d & D86136 & -1.7 & $\begin{array}{l}\text { Protein phosphatase implicated in Alzheimer's disease resulting in tau } \\
\text { hyperphosphorylation (Sun et al., 2003) }\end{array}$ \\
\hline 5 & Calcium/calmodulin-dependent protein kinase II & $\begin{array}{l}\text { Camk2d/Cam- } \\
\quad \text { KIld }\end{array}$ & NM_012519 & -1.7 & CamKIl is involved in signaling cascades important for memory formation \\
\hline 6 & REST corepressor 2 & Reor2 & BF285211 & -1.7 & $\begin{array}{l}\text { Functions to complex with other proteins, such as HDACs, to silence } \\
\text { transcription }(\text { Qiu, 2009) }\end{array}$ \\
\hline 7 & Nuclear factor of activated T-cells & Nfatc4 & BG377358 & -1.6 & $\begin{array}{l}\text { Transcription factor whose inhibition resulted in impaired extinction } \\
\text { behavior (de la Fuente et al., 2011) }\end{array}$ \\
\hline 8 & SMART/HDAC1 associated repressor protein & SPEN & BI295169 & -1.6 & Transcription repressor complex \\
\hline 9 & Jumonji containing domain 3 & Jmjd3 & BE118720 & -1.6 & Histone H3 lysine 27 demethylase (De Santa et al., 2009) \\
\hline 10 & Nuclear receptor binding SET domain protein 1 & Nsd1 & BE116223 & -1.5 & Histone H3 lysine 36 methyltransferase (Lucio-Eterovic et al., 2010) \\
\hline 11 & $\begin{array}{l}\text { Similar to SWI/SNF-related matrix-associated actin-dependent } \\
\text { regulator of chromatin c2 }\end{array}$ & LOC685179 & AW528026 & -1.5 & SWI/SNF complex destabilizes histone-DNA interaction \\
\hline 12 & Histone deacetylase 7a & HDAC7a & Al103918 & -1.4 & Removes acetyl groups from lysine residues of histone tails \\
\hline 13 & Histone deacetylase 10 & HDAC10 & Al236142 & -1.3 & Removes acetyl groups from lysine residues of histone tails \\
\hline 14 & Myeloid/lymphoid or mixed-lineage leukemia 1 & MII1 & AA965060 & -1.3 & $\begin{array}{l}\text { Histone } \mathrm{H} 3 \text { lysine } 4 \text { methyltransferase that positively regulates memory } \\
\text { formation (Gupta et al., 2010) }\end{array}$ \\
\hline 15 & Cbp/p300-interacting transactivator & Cited4 & Al556378 & -1.3 & Transcription coactivators containing histone acetyltransferase domain \\
\hline 16 & DNA methyltransferase $3 a$ & Dnmt3a & Al029751 & -1.2 & $\begin{array}{l}\text { Methylates DNA at CpG sites and implicated in LTM formation (Levenson } \\
\text { et al., 2006; LaPlant et al., 2010) }\end{array}$ \\
\hline 17 & Euchromatic histone lysine $\mathrm{N}$-methyltransferase 2 & $\begin{array}{c}\text { Ehmt2, G9a, } \\
\text { KMT1C }\end{array}$ & AW434474 & -1.3 & $\begin{array}{l}\text { Histone H3 lysine } 9 \text { methyltransferase implicated in addiction and } \\
\text { mental disorders (Schaefer et al., 2009; Maze et al., 2010; Covington } \\
\text { et al., 2011) }\end{array}$ \\
\hline 18 & Transcription regulator SIN3a & $\sin 3 a$ & BE095920 & -1.2 & Regulates transcription through its interaction with HDAC1 \\
\hline 19 & Sirtunin 7 & Sirt7 & AA892780 & -1.2 & NAD-dependent histone deacetylase \\
\hline 20 & Histone deacetylase 5 & Hdac5 & BF403027 & -1.2 & Removes acetyl group from lysine residues of histone tails \\
\hline 21 & SET domain containing lysine methyltransferase 8 & LOC687538 & Al235220 & -1.1 & Lysine methyltransferase \\
\hline 22 & Dot1 like histone methyltransferase & Dot1 & BG381046 & -1.1 & Histone H3 lysine 79 methyltransferase \\
\hline 23 & Similar to Jumonji/ARID domain-containing protein $1 C$ & KDM5C/JARID1C & AA955145 & -1.1 & $\begin{array}{l}\text { Histone } \mathrm{H} 3 \text { lysine } 4 \text { demethylase whose inactivation causes mental } \\
\text { retardation syndrome (Franklin and Mansuy, 2011) }\end{array}$ \\
\hline 24 & Transcription repressor Sin3b & $\sin 3 b$ & AA849552 & -1.1 & Transcription repressor which associates with HDAC \\
\hline 25 & Histone deacetylase 3 & Hdac3 & NM_053448 & -1.1 & Removes acetyl groups from lysine residue on histone tails \\
\hline 26 & Euchromatic histone methyltransferase 1 & $\begin{array}{l}\text { Ehmt1, GLP, } \\
\text { KMT1D }\end{array}$ & BM389055 & -1.0 & $\begin{array}{l}\text { Forms surpressor complex with Ehmt2 to methylate istone H3 lysine } 9 \\
\text { (Shinkai and Tachibana, 2011) }\end{array}$ \\
\hline 27 & Histone deacetylase 2 & Hdac2 & BF394504 & -1.0 & $\begin{array}{l}\text { Removes acetyl group from lysine residues of histone tails and has been } \\
\text { implicated in regulating memory formation (Guan et al., 2009) }\end{array}$ \\
\hline 28 & Sirtunin 4 & Sirt4 & BF546537 & -1.0 & NAD-dependent histone deacetylase \\
\hline 29 & Sirtunin 2 & Sirt2 & AA799614 & 1.0 & NAD-dependent histone deacetylase \\
\hline 30 & cAMP-responsive element-binding protein-like 2 & Crebl2 & BE113210 & 1.0 & $\begin{array}{l}\text { Transcription activator that participates in several signaling mechanism } \\
\text { pivotal for LTM formation }\end{array}$ \\
\hline 31 & Histone deacetylase 1 & Hdac1 & Al180339 & 1.0 & $\begin{array}{l}\text { Removes acetyl groups from lysine residue of histone tails and has been } \\
\text { implicated in LTM formation (Guan et al., 2009) }\end{array}$ \\
\hline 32 & Reelin & Reln & NM_080394 & 1.1 & Reelin protein helps modulate synaptic plasticity \\
\hline 33 & p300/CBP-associated factor & PCAF & 283046 & 1.1 & Transcription coactivator that is critical for long term memory formation \\
\hline 34 & Histone deacetylase 11 & Hdac11 & Al101322 & 1.1 & Removes acetyl groups from lysine residues of histone tails \\
\hline 35 & DNA methyltransferase 1 & DNMT1 & Al179516 & 1.1 & $\begin{array}{l}\text { Methylates DNA at CpG sites and regulates synaptic plasticity (Feng et al., } \\
\text { 2010) }\end{array}$ \\
\hline 36 & Early growth response 1 & Egr1/Zif268 & NM_012551 & 1.2 & $\begin{array}{l}\text { Immediate-early gene activated in response to learning that serves as a } \\
\text { transcription factor. }\end{array}$ \\
\hline 37 & Brain-derived neurotrophic factor & Bdnf & NM_012513 & 1.3 & Immediate-early response gene \\
\hline 38 & DNA methyltransferase 3B & Dnmt3b & BF562135 & 1.9 & Methylates DNA at CpG site \\
\hline
\end{tabular}

Histone $\mathrm{H} 3$ lysine methylation is regulated in the $\mathrm{EC}$ during fear memory consolidation

We investigated whether histone $\mathrm{H} 3$ lysine methylation levels were also altered in the EC after CCF training. At $1 \mathrm{~h}$ after CCF training, we observed significant increases in $\mathrm{H} 3 \mathrm{~K} 9 \mathrm{me} 2$ intensity levels in the EC, but not with context exposure alone (Fig. 1C).
Conversely, $\mathrm{H} 3 \mathrm{~K} 4 \mathrm{me} 3$ intensity levels were increased in the EC after CCF training, and a trend toward an increase was observed with context exposure alone compared with naive controls (Fig. $1 C)$. Western blotting analysis also revealed a significant increase in $\mathrm{H} 3 \mathrm{~K} 9 \mathrm{me} 2$ levels in the $\mathrm{EC}$, whereas $\mathrm{H} 3 \mathrm{~K} 4 \mathrm{me} 3$ levels were significantly increased in the EC after context exposure alone or 
A

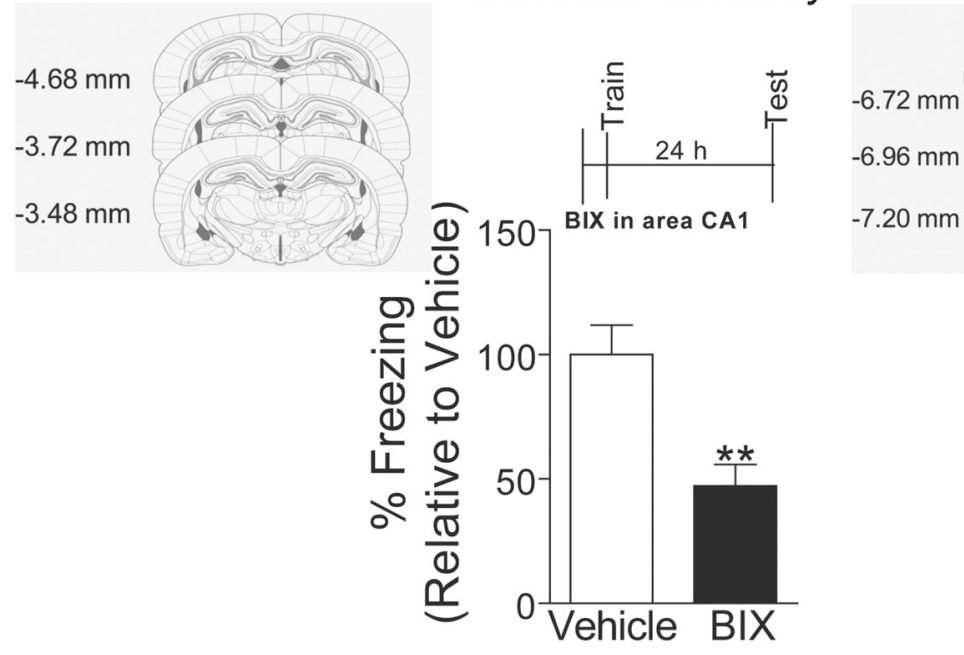

B

Behavior-Test Day 1

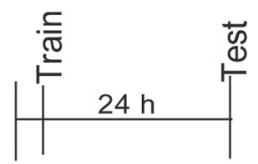

BIX or UNC0224 in EC

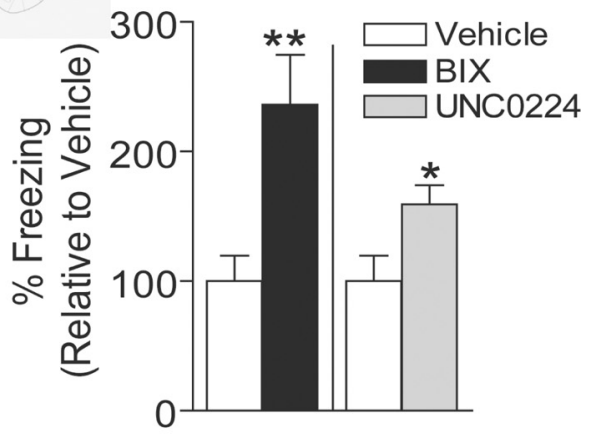

E

Cued fear conditioning

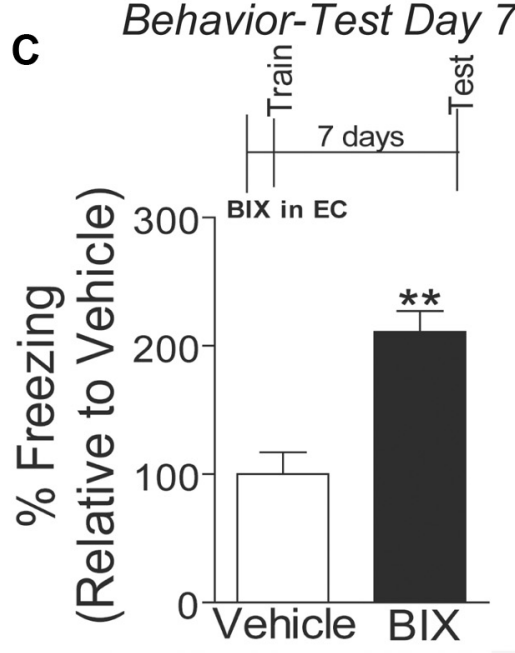

D Behavior-Test Day 1

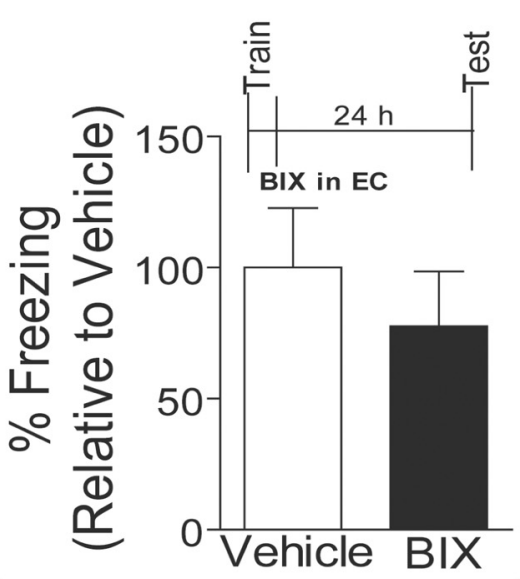

\section{Extinction Behavior}

$\mathbf{F}$

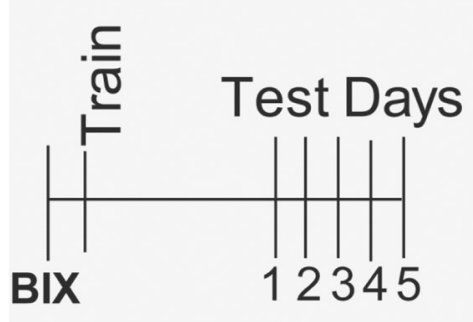

$\square-$ Vehicle- Context + Shock

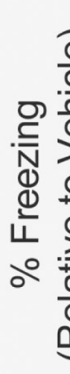

$\leftarrow$ BIX- Context + Shock

$\overbrace{}^{600}$
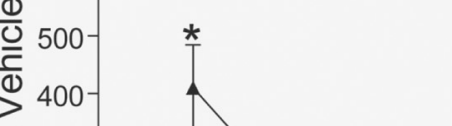

우 $300-$

$\stackrel{100}{2}$

売 $200-$

0

0
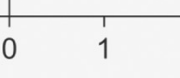

Test Days

Figure 2. Effect of G9a/GLP inhibition on fear memory consolidation and extinction. $A$, The diagram represents histology of animals randomly chosen from the experimental group to confirm intra-CA1 needle tip infusion sites. On Test Day 1, BIX01294 (BIX)-CA1-treated animals show less freezing compared with vehicle-treated animals $\left(t_{(23)}=3.63 ; p<0.01 ; n=12-13\right)$. $\boldsymbol{B}$, The diagram represents histology of animals randomly chosen from the experimental group to confirm intra-EC needle tip infusion sites. BIX-EC-treated animals froze significantly more than the vehicle-treated animals on Test Day $1\left(t_{(17)}=3.053 ; p<0.01 ; n=9-10\right)$. UNC0224-EC infusions confirmed the effect of BIX-EC treatment on freezing behavior on Test Day $1\left(t_{(19)}=2.362 ; p<\right.$ $0.05 ; n=10-11)$. C, BIX-EC-treated animals froze significantly more than vehicle-treated animals on Test Day $7\left(t_{(9)}=4.630 ; p<0.01 ; n=6-7\right)$. D, BIX-EC treatment at $6 \mathrm{~h}$ after contextual conditioned fear has no affect on freezing behavior $(n=6-7)$. $E$, After cued fear conditioning, on Test Day 1 BIX-EC-treated animals display significantly more freezing behavior compared with vehicle-treated animals $\left(t_{(19)}=2.276 ; p<0.05 ; n=9-12\right)$. Error bars are SEM. $F$, BIX-EC-treated animals during extinction revealed a significant day effect $\left(F_{(4,51)}=13.91 ; p<0.0001\right)$ and drug effect $\left(F_{(4,51)}=18.10 ; p<0.0001\right)$ compared with vehicle-treated animals. Line regression analysis revealed a significantly enhanced rate of extinction in BIX-EC-treated animals compared with vehicle-treated animals $(F=20.9462 ; p<0.0001 ; n=7)$. Asterisks indicate significance compared to naive control group. 
CCF training compared with naive controls (Fig. 1D). These results suggest that, in contrast to the hippocampus, $\mathrm{H} 3 \mathrm{~K} 9 \mathrm{me} 2$ regulation in the $\mathrm{EC}$ was specific to the associative learning paradigm (Fig. 1B). Additionally, these findings are the first report of an epigenetic modification regulated in the EC during memory consolidation.

We next determined how long-lasting were the changes in histone $\mathrm{H} 3$ lysine methylation in the EC after CCF training. We hypothesize that HKM may serve as a candidate molecular mechanism supporting a persistent transcriptional signature in the EC that is necessary for LTM. Thus, we performed another series of Western blotting analyses of global HKM levels in the EC at $24 \mathrm{~h}$ after CCF training. We found no significant changes in $\mathrm{H} 3 \mathrm{~K} 9 \mathrm{me} 2$ levels in the EC after context exposure alone or CCF training (Fig. $1 E$ ), suggesting that $\mathrm{H} 3 \mathrm{~K} 9 \mathrm{me} 2$ regulation was transient and reversible in the EC. However, we observed a significant decrease in $\mathrm{H} 3 \mathrm{~K} 4 \mathrm{me} 3$ levels in the $\mathrm{EC}$ at $24 \mathrm{~h}$ long after context exposure alone or CCF training compared with naive controls (Fig. $1 E)$. These results are in contrast to our previous findings in the hippocampus wherein H3K4me3 levels were dynamically and transiently activated, whereas $\mathrm{H} 3 \mathrm{~K} 9 \mathrm{me} 2$ levels were persistently altered after exposure to a novel context or fear conditioning (Gupta et al., 2010). Together, these findings are the first report of a long-lasting epigenetic modification in the EC produced by a learning experience. Based on what we know about the effects of HKM, these changes translate into the basic idea that memory consolidation triggers both activation and repression of gene transcription in post-mitotic neurons.

\section{G9a/GLP blockade in the hippocampus interferes with LTM and in the EC enhances memory consolidation and extinction}

Thus far, our studies show regulation of H3K9me2 in both the hippocampus and the EC in response to CCF learning. Thus, we next sought to determine the effect of pharmacologically inhibiting the G9a/GLP $\mathrm{H} 3 \mathrm{~K} 9 \mathrm{me} 2$-specific dimethyltransferases in the hippocampus or the EC during memory consolidation and assessed effects on LTM formation. For the hippocampus experiments, BIX01294, a potent and selective noncompetitive inhibitor of G9a/GLP activity (Kubicek et al., 2007), was infused bilaterally into area CA1 $1 \mathrm{~h}$ before CCF training (Fig. $2 \mathrm{~A}$ ). Saline-infused animals served as vehicle controls. We first assessed freezing behavior during CCF training and observed no differences in freezing levels, thus eliminating effects on hippocampus-dependent memory acquisition (data not shown). On Test Day 1, both groups of animals were reexposed
B H3K9me2

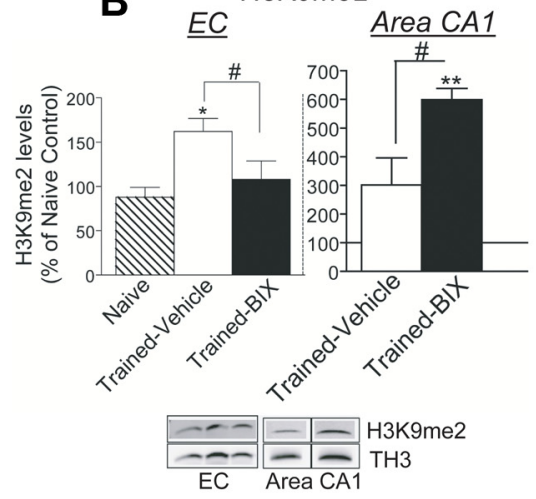

D

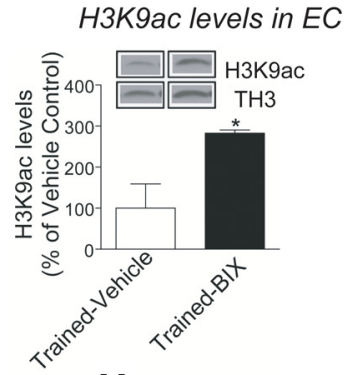

$\mathbf{F}$

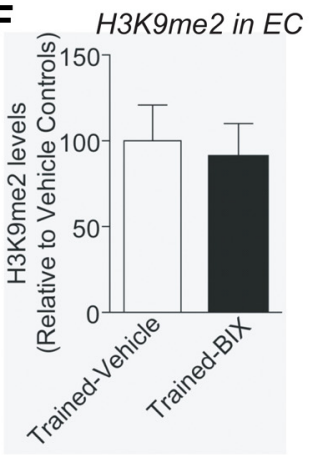

G
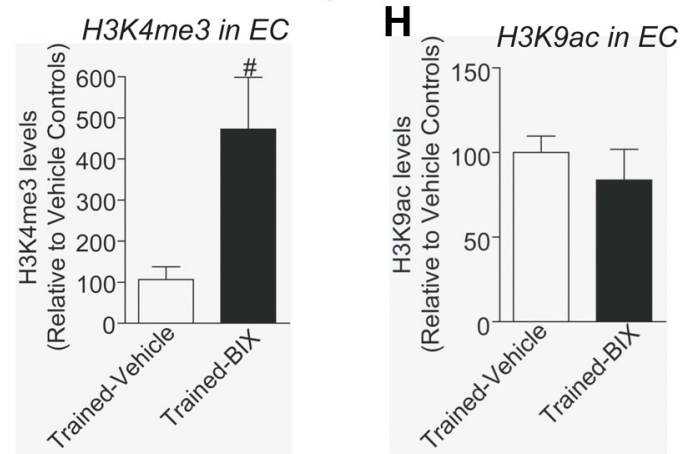

Figure 3. $\mathrm{G} 9 \mathrm{a} / \mathrm{GLP}$ inhibition in the EC alters histone lysine methylation in the EC and area CA1 after fear conditioning. $\boldsymbol{A}$, Experimental design with data presented in $\boldsymbol{B}-\boldsymbol{D}$. $\boldsymbol{B}$, Significant increases in $\mathrm{H} 3 \mathrm{~K} 9 \mathrm{me} 2$ levels in the $\mathrm{EC}$ of vehicle-EC-treated animals $\left(t_{(18)}=2.810 ; p<0.05\right)$ compared with naive controls. BIX-EC treatment blocked the increase in H3K9me2 levels in the $\mathrm{EC}$ compared with vehicle-EC-treated animals $\left(t_{(22)}=2.190 ; p<0.05 ; n=5-14\right)$. BIX-EC infusion further enhanced H3K9me2 $n=4-6)$. C, H3K4me3 levels increased in the $\mathrm{EC}$ after vehicle treatment $\left(F_{(2,25)}=5.153 ; p<0.05 ; n=7-14\right)$ and also increased with BIX treatment $\left(t_{(21)}=2.37 ; p<0.05 ; n=7-14\right)$. H3K4me3 levels increased in area CA1 of vehicle-EC-treated animals $\left(t_{(3)}=3.411 ; p<0.05\right)$ and BIX-EC-treated animals $\left(t_{(5)}=10.81 ; p<0.001 ; n=4-6\right)$ compared with naive controls. D, H3K9ac levels increased in the $\mathrm{EC}$ of BIX-treated animals $\left(t_{(2)}=3.071 ; p<0.05 ; n=3\right)$. $\boldsymbol{E}$, Experimental design with data presented in $(n=3)$. G, Significant increase in H3K4me3 levels in the EC of BIX-CA1-infused animals compared with vehicle-treated animals (Student's $t$ test, ${ }^{\#} p<0.05 ; n=3$ ). $\boldsymbol{H}$, There was no difference in H3K9ac levels in the EC of BIX-CA1-infused animals compared with vehicle-treated animals $(n=3)$. Error bars are SEM. Solid lines represent normalized naive control levels. * Significance

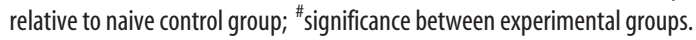

to the training chamber at $24 \mathrm{~h}$, and freezing behavior was assessed. We observed that BIX01294-CA1-infused animals displayed significantly less freezing behavior compared with vehicle controls (Fig. 2A). These findings suggest that G9a/GLPmediated $\mathrm{H} 3 \mathrm{~K} 9 \mathrm{me} 2$ methylation in the hippocampus is crucial for LTM formation.

To determine the effect of G9a/GLP inhibition in the EC on LTM, bilateral intra-EC cannulated animals (Fig. $2 B$ ) were administered BIX01294 or vehicle-saline $1 \mathrm{~h}$ before CCF training, and freezing behavior was assessed $24 \mathrm{~h}$ later. On Test Day 1, BIX01294-EC-infused animals displayed significantly more freezing behavior compared with vehicle controls (Fig. 2 B), sug- 
gesting that in the EC G9a/GLP, activity may serve to negatively regulate memory consolidation. EC infusions with the G9a specific inhibitor UNC0224 (Liu et al., 2009) confirmed our BIX01294 findings (Fig. 2B). We also investigated the temporal duration of elevated freezing levels with BIX01294-EC infusion, which is a direct readout of LTM retention. Animals experienced the CCF training paradigm and were returned to their home cage. On Test Day 7, we found that BIX01294-EC-infused animals still displayed elevated freezing compared with vehicle controls (Fig. 2C), suggesting that CCF memory enhancement produced by G9a/GLP inhibition in the EC during memory consolidation lasts for up to $7 \mathrm{~d}$.

To exclude the possibility of an adverse effect of the BIX01294 drug infusion in the EC during LTM formation, we performed the following control experiments. First, no significant differences in freezing levels were observed during CCF training after BIX01294-EC infusion before training, thus eliminating any adverse effects on CCF memory acquisition (data not shown). Second, animals were infused with BIX01294 or vehicle in the EC at $6 \mathrm{~h}$ after CCF training, a time point that was well outside the memory consolidation time window, and freezing behavior was assessed $24 \mathrm{~h}$ later. On Test Day 1, no significant differences in freezing levels were observed (Fig. 2D), indicating that BIX01294 infusion alone does not induce an enhanced fearful response (freezing). Together, these results suggest that the behavioral effects of BIX01294, in the hippocampus or the EC, are specific to inhibition of G9a/GLP activity during the consolidation of CCF memories.

Overall our studies are demonstrating complex regulation of G9a/GLP activity in memory-related brain regions during LTM consolidation. However, we could not ignore the fact that manipulation of G9a/GLP activity in the EC may have resulted in a deficit in the extinction of the fear memory per se rather than enhanced memory formation. Thus, another cohort of BIX01294-EC-infused animals was subjected to an extinction trial induced by $5 \mathrm{~min}$ reexposure to the training chamber in the absence of the footshock for 5 consecutive days after CCF training. We found that BIX01294-EC-treated animals displayed significant increases in freezing behavior on Test Day 1 and Test Day $2\left(t_{(10)}=3.377 ; p<0.01 ; t_{(10)}=2.535 ; p<0.05\right)$, which was not apparent on Test Day 3 (Fig. 2 F). Furthermore, G9a/GLP inhibition in the EC resulted in the significant enhancement of the extinction rate compared with the vehicle controls.

In addition to the hippocampus, the $\mathrm{EC}$ also serves as a major nodal point for exchange of sensory information between the amygdala and the cortex (Maytal et al., 1989; Pitkanen et al., 2000; Majak and Pitkanen, 2004). Thus, we assessed the effect of G9a/ GLP inhibition in the EC on freezing behavior during retrieval of an amygdala-dependent cued fear conditioning (CFC) learning task. We found that bilateral EC infusion of BIX01294 at $1 \mathrm{~h}$ before CFC significantly increased freezing levels in response to cued-tone alone on Test Day 1 compared with vehicle-saline controls (Fig. 2E). These data suggest that G9a/GLP activity within the EC mediates both hippocampal- and amygdaladependent LTM formation. It is important to note that G9a/GLP blockade restricted to area CA1 did not interfere with cued LTM formation (data not shown; $t_{(10)}=0.4908 ; p=0.6341 ; n=6$ ).

G9a/GLP activity in the EC regulates posttranslational histone modifications in both the EC and the hippocampus during memory consolidation

Since G9a/GLP activity could not be measured because no specific assay is available, we confirmed the effect of G9a/GLP inhibition in the $\mathrm{EC}$ and area CA1 during memory consolidation by measuring global $\mathrm{H} 3 \mathrm{~K} 9 \mathrm{me} 2$ methylation levels at $1 \mathrm{~h}$ after CCF
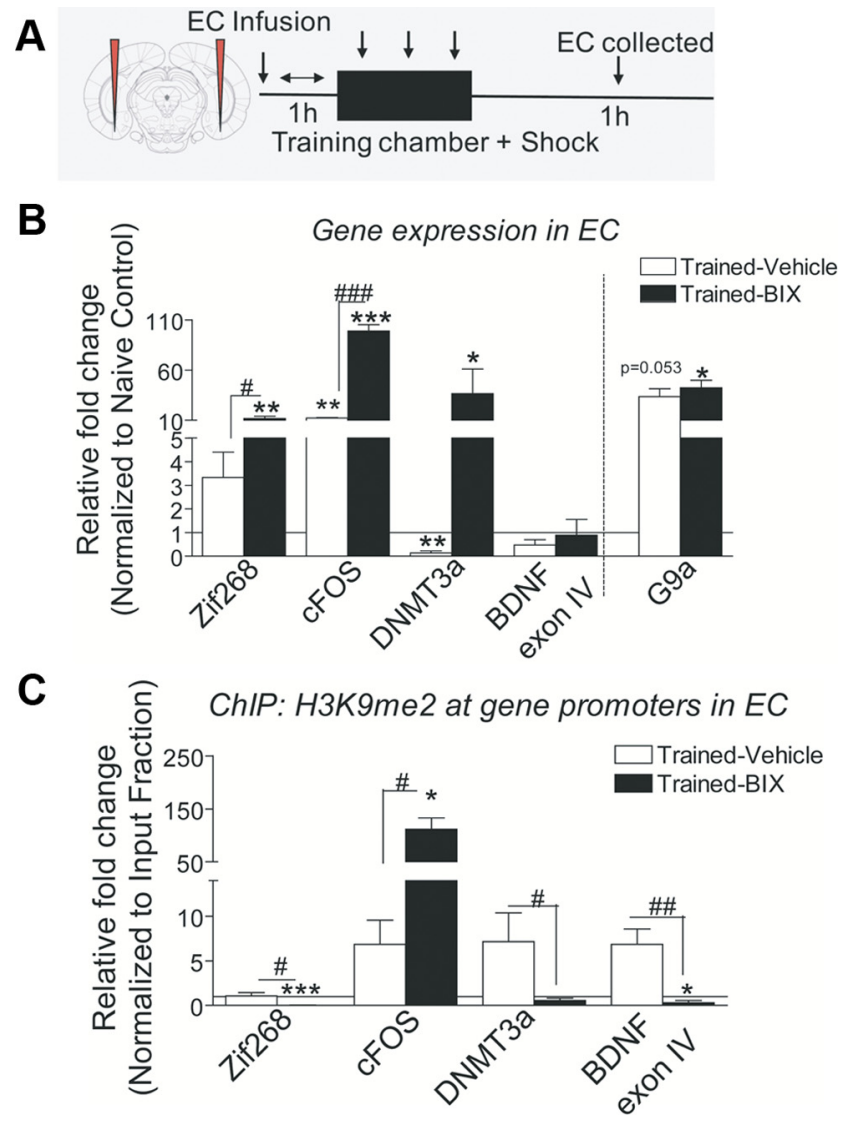

Figure 4. G9a/GLP is increased at gene promoters in the $\mathrm{EC}$ after fear conditioning. $A$, The diagram outlines the experimental design with data shown in $\boldsymbol{B}$ and $\boldsymbol{C}$. $\boldsymbol{B}$, Significant upregulation in Zif268 $\left(F_{(2,8)}=10.77 ; p<0.01\right)$ and $c F O S\left(F_{(2.5)}=166.7 ; p<0.001\right)$ mRNA levels in the $\mathrm{EC}$ after BIX01294 or vehicle treatment $(n=3-4)$. DNMT3 a mRNA levels were significantly downregulated in the $\mathrm{EC}$ of vehicle-treated animals compared with naive controls $\left(t_{(2)}=10.4\right.$; $p<0.01)$. G9a mRNA levels were increased in the EC of vehicle-treated animals compared with naive controls $\left(t_{(2)}=4.132 ; p=0.053\right)$ and were also enhanced in the EC of BIX-EC-treated animals compared with naive controls $\left(t_{(2)}=5.545 ; p<0.05\right)$. No alterations were observed in BDNF exon IV mRNA levels in the EC. C, ChIP samples taken from the EC revealed significant decreases in H3K9me2 levels at the Zif268 $\left(t_{(4)}=69.51 ; p<0.0001\right)$ and BDNF exon $I V\left(t_{(4)}=\right.$ $2.919 ; p<0.05)$ gene promoters with BIX treatment compared with naive controls. Significant decreases in H3K9me2 levels were observed at the Zif268 $\left(t_{(7)}=3.202 ; p<0.05\right)$, DNMT3a $\left(t_{(6)}=2.777 ; p<0.05\right)$, and BDNF exon $I V\left(t_{(6)}=5.023 ; p<0.01\right)$ gene promoters in the EC of BIX-treated animals compared with vehicle-treated animals. There were significant increases in $\mathrm{H} 3 \mathrm{~K} 9 \mathrm{me} 2$ levels at the CFOS gene promoter in the EC of BIX-treated animals compared with vehicle-treated animals $\left(t_{(3)}=3.807 ; p<0.05\right)$ or naive controls $\left(t_{(2)}=5.203 ; p<0.05 ; n=\right.$ $3-4)$. Error bars are SEM. Solid lines represent normalized naive control levels. *Significance

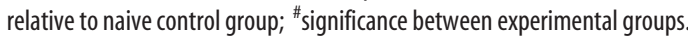

(experimental design outlined in Fig. 3A). Naive-saline-infused animals served as controls for the vehicle- and BIX01294-treated behavioral groups. As expected, BIX01294-EC infusion significantly attenuated $\mathrm{H} 3 \mathrm{~K} 9 \mathrm{me} 2$ levels in the EC during CCF consolidation compared with vehicle-EC infusion, thus confirming successful inhibition of G9a/GLP activity in the EC (Fig. 3B). Intriguingly, BIX01294-EC infusion resulted in a significant increase in $\mathrm{H} 3 \mathrm{~K} 9 \mathrm{me} 2$ levels in area CA1 compared with vehicle-EC treatment (Fig. 3B). These surprising results indicate that cellular and molecular inputs, in the form of G9a/GLP activity, from the EC can alter HKM regulation in the hippocampus during memory consolidation.

Posttranslational histone modifications have been shown to be both mutually exclusive and complementary in some cell systems (Suganuma and Workman, 2008; Lee et al., 2010). Thus, we 
next investigated whether G9a/GLP inhibition in the EC influenced regulation of other posttranslational histone modifications in the EC and area CA1 after CCF training. Western blotting analysis revealed significant increases in the transcription active marks, H3K4me3 (Fig. 3C) and H3K9ac (Fig. 3D), in the EC of vehicle-treated animals compared with control animals. We also observed an enhancement in $\mathrm{H} 3 \mathrm{~K} 4 \mathrm{me} 3$ levels in the $\mathrm{EC}$ with BIX01294 treatment compared with vehicle-treated animals. In area CA1, we found that H3K4me3 levels were significantly elevated in the EC of BIX01294treated animals compared with vehicle controls (Fig. 3C). These results are interesting and suggest an alternate mechanism through which G9a/GLP inhibition in the EC may promote memory consolidation: enhancement of transcriptional activity via regulation of $\mathrm{H} 3 \mathrm{~K} 4 \mathrm{me} 3$ and H3K9ac marks in both the EC and hippocampus. We also observed that BIX01294-CA1 infusions (Fig. 3E) altered $\mathrm{H} 3 \mathrm{~K} 4 \mathrm{me} 3$, but not $\mathrm{H} 3 \mathrm{~K} 9 \mathrm{me} 2$ or $\mathrm{H} 3 \mathrm{~K} 9 \mathrm{ac}$, levels in the EC with CCF training (Fig. $3 F-H)$, raising the possibility that G9a/ GLP-mediated cellular and molecular inputs from the hippocampus to the EC may also exist during memory consolidation.

\section{G9a/GLP activity in the EC alters $\mathrm{H} 3 \mathrm{~K} 9 \mathrm{me} 2$ levels at gene promoters during memory consolidation}

Based on extensive research in the field and our microarray analysis, we identified regulation of four genes in the hippocampus that are important for the process of memory consolidation: the protooncogene, cFOS, Zif268 (also known as the EGR-1, NGFI-A, Krox 24, TIS 8, ZENK), DNMT3a (DNA methyltransferase 3a), and BDNF exon IV (Colombo, 2004; Knapska and Kaczmarek, 2004; Korzus et al., 2004; Levenson et al., 2006; Lubin et al., 2008; Lonergan et al., 2010). Although these genes have been shown to be important regulators of LTM formation within the hippocampus, they have not yet been characterized within the EC during CCF memory consolidation. Thus, we characterized expression of these memory-related genes for the first time in the EC. Gene expression analysis revealed that DNMT3a mRNA levels were significantly decreased in vehicle-EC-treated animals, whereas $c F O S$ mRNA levels were increased, compared with naive controls (Fig. 4B). In BIX01294-EC-treated animals, Zif268, cFOS, and DNMT3a mRNA levels were increased compared with vehicle-EC controls (Fig. $4 B)$. No changes were observed in BDNF exon IV mRNA levels. In agreement with previous studies suggesting that G9a/GLP activity may serve to negatively regulate its own gene expression (Maze et al., 2010), we found significant increases in G9a mRNA levels in the EC with G9a/GLP inhibition (Fig. 4B).

At the chromatin level, ChIP analysis revealed a significant decrease in H3K9me2 levels at the Zif268, DNMT3a, and BDNF exon
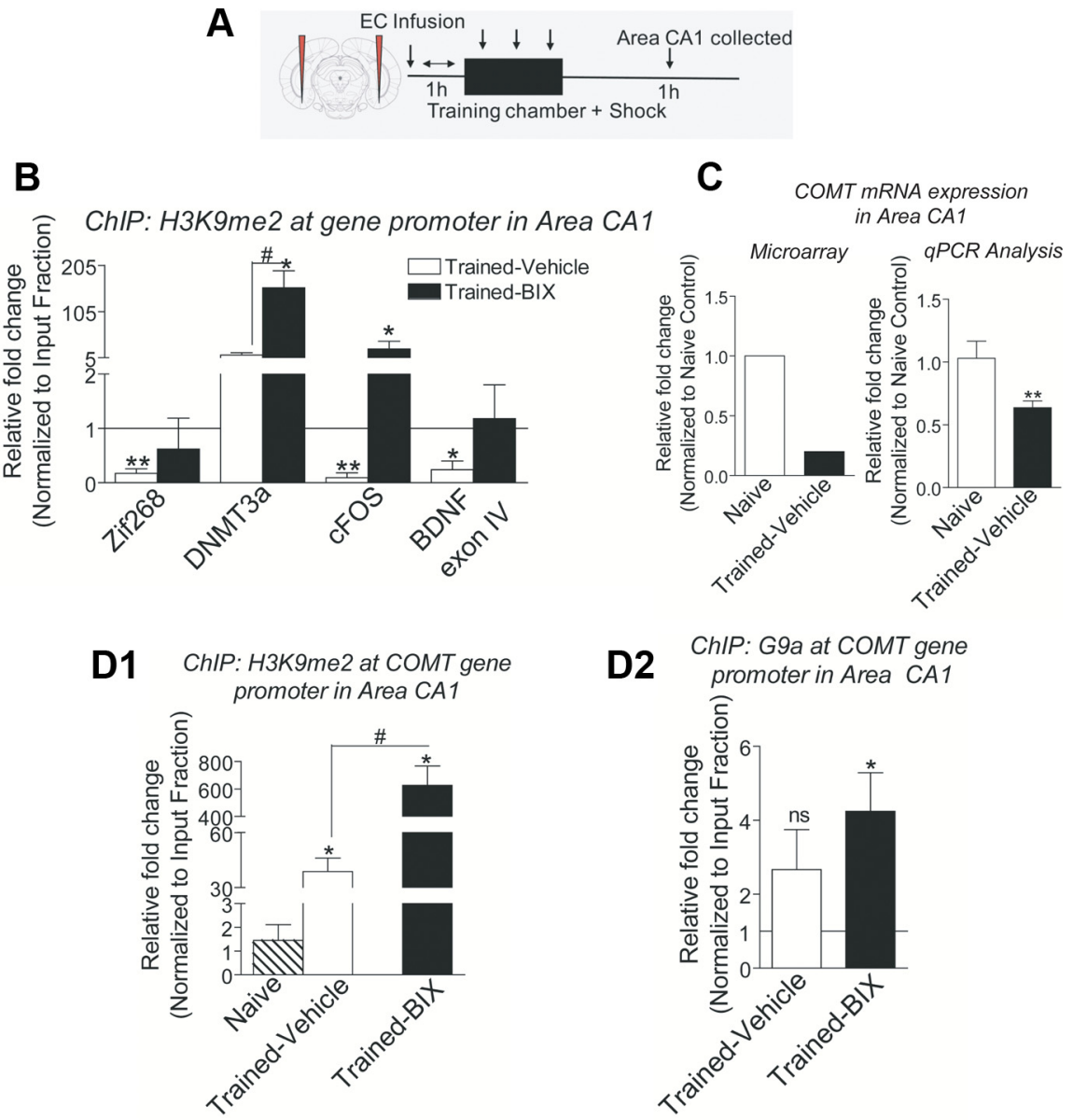

Figure 5. $G 9 \mathrm{a} / \mathrm{GLP}$ inhibition in the $\mathrm{EC}$ alters gene expression in area $C A 1$ after fear conditioning. $A$, Experimental design with data presented in $\boldsymbol{B}-\mathbf{D} 2$. $\boldsymbol{B}$, ChIP analysis revealed significant decrease in H3K9me2 levels at the Zif268 $\left(t_{(3)}=2.777 ; p<0.05\right), \mathrm{CFOS}\left(t_{(2)}=\right.$ $10.02 ; p<0.01)$, and $B D N F$ exon $I V\left(t_{(3)}=4.764 ; p<0.05\right)$ gene promoters in area CA1 of vehicle-EC-treated animals compared with the

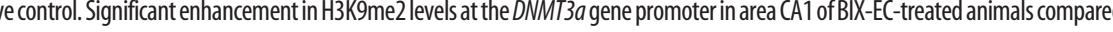
COMTmRNA levels in area CA1 of CCF-treated animals compared with naive controls $\left(t_{(10)}=3.241 \cdot p<0.01 \cdot n=4-5\right)$. D1, Significant enrichment of $\mathrm{H} 3 \mathrm{~K} 9 \mathrm{me} 2$ at the COMT gene promoter in vehicle-treated animals relative to naive controls $\left(t_{(2)}=5.098 ; p<0.05 ; n=\right.$ 4-5), which were further enhanced at the COMT promoter in area CA1 of BIX-EC-treated animals compared with vehicle-treated animals $\left(t_{(5)}=3.503 ; p<0.05\right)$ and naive controls $\left(t_{(3)}=4.415 ; p<0.05\right)$. D2, Significant enhancement of G9a levels at COMT gene promoter in BIX-EC-treated animals compared with naive controls $\left(t_{(3)}=3.112 ; p<0.05\right)$. Error bars are SEM. The solid line represents normalized naive controls. *Significance relative to naive control group; ${ }^{\#}$ significance between experimental groups.

IV gene promoters in BIX01294-EC-treated animals compared with vehicle-EC-treated animals (Fig. 4C). Furthermore, H3K9me2 levels at the Zif268 and BDNF exon IV gene promoters in BIX01294-ECtreated animals correlated with increased mRNA expression (Fig. $4 C)$. We observed significant increases in $\mathrm{H} 3 \mathrm{~K} 9 \mathrm{me} 2$ occupancy at the $c F O S$ gene promoter in the EC of BIX01294-EC-treated animals compared with vehicle-EC or naive controls (Fig. 4C), suggesting that an alternate transcriptional mechanism may be driving $c F O S$ gene expression in the EC. Together, these findings provide additional insights into the molecular mechanism by which G9a/GLP inhibition in the EC serves to promote LTM formation: positive alterations in the transcriptional regulation of memory permissive genes in the EC during memory consolidation.

G9a/GLP activity in the EC differentially regulates $\mathrm{H} 3 \mathrm{~K} 9 \mathrm{me} 2$ levels at gene promoters in the hippocampus during memory consolidation

To determine the effects of G9a/GLP inhibition in the EC on hippocampal gene transcription during memory consolidation, a 


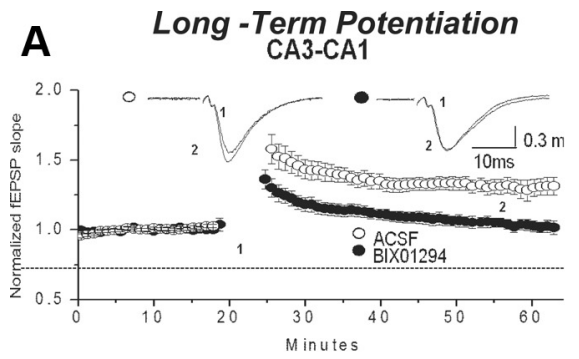

B

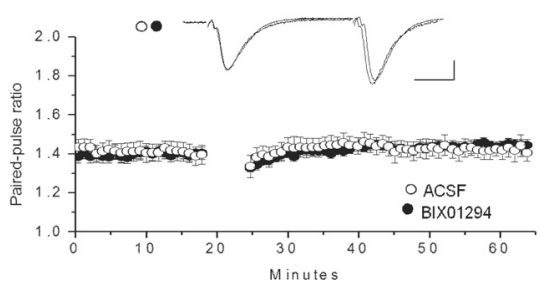

Long -Term Potentiation

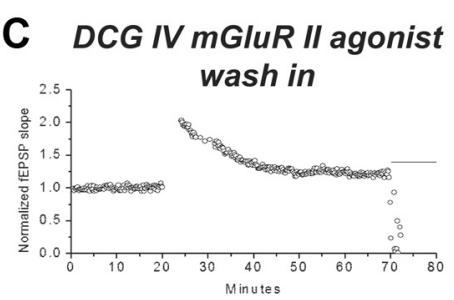

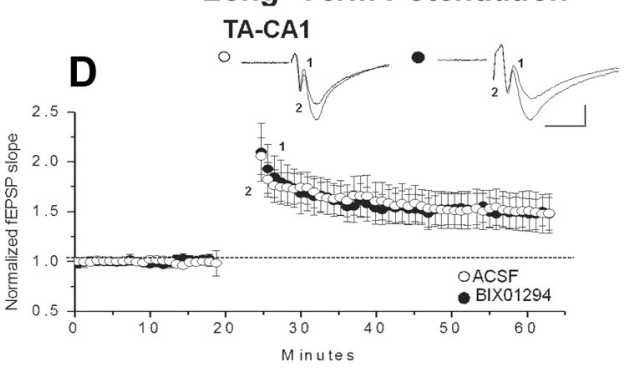

E
Paired Pulse Ratio

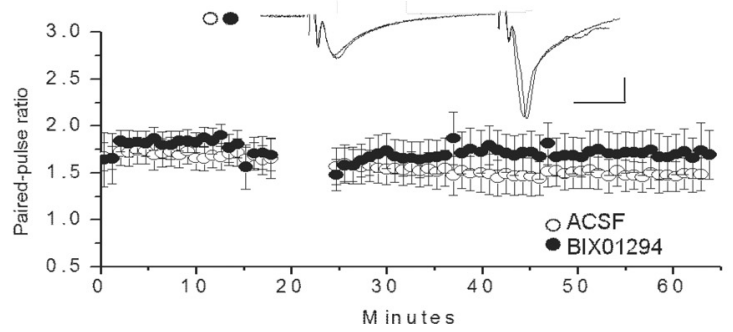

Figure 6. G9a/GLP inhibition differentially affects L-LTP at the Schaffer collateral synapses and temporoammonic synapses. $\boldsymbol{A}$, BIX01294 decreased the magnitude of L-LTP at CA3-CA1 synapses (ACSF, $132 \pm 2 \%$; BIX01294, $105 \pm 3 \%$; ACSF vs BIX01294, $p<0.05 ; n=8$ ). $B$, BIX02194 treatment does not alter paired-pulse ratios at SC-CA1 synapses (ACSF, $1.41 \pm 0.04 ;$ BIX02194, $1.40 \pm .0 .02 ;$ ACSF vs BIX01294, $p>0.05 ; n=8$ ). C, BIX01294 treatment does not effect the magnitude of L-LTP at the TA-CA1 synapses (ACSF, $152 \pm 17 \%$; BIX01294, 152 $\pm 15 \%$; ACSF vs BIX01294, $p>0.05 ; n=6$ ). D, BIX01294 does not alter paired-pulse ratios at TA-CA1 synapses (ACSF, $1.70 \pm 0.13 ;$ BIX01294, 1.8 $\pm .0 .12 ; A C S F$ vs BIX01294, $p>0.05 ; n=5-6$ ). $\boldsymbol{E}$, The application of the group II metabotropic glutamate receptor agonist DCG-IV confirms isolation of TA synapses. Error bars are SEM.

ChIP study was undertaken using hippocampal tissue samples from the same cohort of animals as described above (Fig. $5 A$ ). We found significant decreases in $\mathrm{H} 3 \mathrm{~K} 9 \mathrm{me} 2$ levels at Zif268, cFOS, and $B D N F$ exon $I V$ gene promoters in area CA1 of vehicle-ECtreated animals that were consistent with previous findings of these genes being actively expressed in the hippocampus during memory consolidation. We found no changes in the $\mathrm{H} 3 \mathrm{~K} 9 \mathrm{me} 2$ levels at Zif268 and BDNF exon IV gene promoters in area CA1 of BIX01294-EC-treated animals (Fig. 5B). These findings are surprising because our initial hypothesis was that, similar to the EC, G9a/GLP inhibition in the EC would promote LTM through positive regulation of memory-permissive genes in the hippocampus. In addition, we found that enhanced global H3K9me2 levels with BIX01294-EC infusion resulted in significant increases in $\mathrm{H} 3 \mathrm{~K} 9 \mathrm{me} 2$ levels at gene promoters such as $c F O S$, and DNMT3a in area CA1, where in the latter correlated with decreased DNMT3a mRNA expression in this brain region (-1.2-fold change, microarray data not shown). Although these data demonstrate the complex nature of G9a/GLP activity in the EC, they strongly suggest a potential role for G9a/GLP epigenetic activity in mediating cortical-hippocampal molecular connectivity at the chromatin level.

On the basis of the data described above, we searched our microarray data for a candidate gene whose expression would be de- creased with increased $\mathrm{H} 3 \mathrm{~K} 9 \mathrm{me} 2$ in the hippocampus to promote LTM produced with G9a/GLP inhibition in the EC. We identified the COMT gene, which was decreased by 1.8 -fold in area CA1 after CCF, which we verified through quantitative PCR analysis (Fig. 5C). Indeed, we found significant enrichment of $\mathrm{H} 3 \mathrm{~K} 9 \mathrm{me} 2$ at the COMT gene promoter with CCF (Fig. 5D1). In addition, H3K9me2 was further enhanced at the COMT promoter in area CA1 of BIX01294-EC-treated animals compared with vehicle-treated and naive controls (Fig. 5D1). G9a levels were also enhanced at the COMT gene promoter in area CA1 of BIX01294-EC-treated animals compared with naive controls (Fig. 5D2). Together, these findings suggest that inhibition of G9a/GLP in EC promotes expression of memory-permissive genes in the $\mathrm{EC}$ and suppression of genes not permissive for memory in the hippocampus during LTM formation.

G9a/GLP inhibition blocks L-LTP at the Schaffer collateral synapses but not at the temporoammonic synapses

Induction of L-LTP at the Schaffer collateral synapses in area CA1 of the hippocampus (SC-CA1) is thought to be the cellular correlate of hippocampusdependent LTM formation in vivo (Yamamoto, 1989). Because G9a/GLP inhibition in area CA1 resulted in decreased freezing behavior, we next sought to determine whether this molecular event was reflected at the synaptic plasticity level. In acutely prepared hippocampal slices from 6- to 8-week-old male rats, we found that bath application of BIX01294 $(1 \mu \mathrm{M})$ did not alter baseline transmission (data not shown; $p>0.05$ ). However, BIX01294 treatment prevented L-LTP induction at SC-CA1 synapses with transmission returning to baseline $30 \mathrm{~min}$ after tetanus (Fig. 6A). Presynaptic release probability measured through paired-pulse ratio (Fig. 6B) showed no differences, eliminating release probability as the cause of the L-LTP deficit (Dobrunz and Stevens, 1997).

On the basis of these physiological data, we next examined the effect of G9a/GLP inhibition on L-LTP at temporoammonic pathway (TA) synapses. The TA pathway initiates in layer III neurons of the EC and project to area CA1 to influence synaptic and behavioral hippocampal output (Remondes et al. 2002, 2004). Group II metabotropic glutamate receptor agonist ((1R,2R)-3-[(1S)-1-amino-2-hydroxy-2-oxoethyl]cyclopropane-1,2-dicarboxylic acid) (DCG-IV) confirmed isolation of TA-CA1 synapses (Fig. 6C) (Cobb et al., 2000). Thus, we found that bath application of BIX01294 did not alter the magnitude of L-LTP generated at TA-CA1 synapses (Fig. 6D) or the paired-pulse ratio (Fig. 6E). Together, these results suggest that G9a/GLP inhibition results in altered L-LTP at specific cellular pathways from the EC to the hippocampus, which also supports the behavioral effects of inhibiting G9a/GLP epigenetic suppressor activity in the hippocampus versus the EC on LTM. 


\section{Discussion}

Extensive research on transcriptional mechanisms recruited during memory consolidation has established that both activation and silencing of gene expression are required for LTM formation. However, the majority of these studies have primarily focused on cellular and molecular mechanisms for transcriptional gene activation, whereas gene-silencing mechanisms have been essentially ignored in this context. Here, we identify an essential role for the G9a/GLP epigenetic suppressor complex in the regulation of transcriptional gene silencing in the hippocampus and in the EC during memory consolidation. We performed functional studies that establish that G9a/GLP activity blockade in the hippocampus impairs LTM formation and L-LTP at the SC-CA1 synapses. In contrast, G9a/GLP blockade in the EC resulted in enhanced LTM and normal L-LTP at the TA-CA1 synapses. In addition, molecular experiments demonstrate that G9a/GLP activity in the EC mediates $\mathrm{H} 3 \mathrm{~K} 9 m e 2-$ dependent repression of specific gene transcripts in both the EC and the hippocampus during memory consolidation. Together, these data implicate the G9a/GLP dimethyltransferase suppressor complex in the coordinated activation and repression of gene transcripts in the EC and the hippocampus that are necessary for the process of LTM formation.

Initial investigations into epigenetic mechanisms such as DNA methylation and histone acetylation in the adult brain have revealed that theses molecular processes are dynamic and transiently activated in the hippocampus, amygdala, and medial prefrontal cortex after fear conditioning (Levenson et al., 2004; Lubin et al., 2008; Guan et al., 2009; Koshibu et al., 2009; Gupta et al., 2010; Monsey et al., 2011). However, these pioneering studies still raise the question as to whether these dynamic epigenetic markings or other chromatin modifications in the adult brain can truly serve as candidate mechanisms involved in the encoding of longlasting stable memories. Our present findings addresses this question, and we found that although the transcription repressive mark $\mathrm{H} 3 \mathrm{~K} 9 \mathrm{me} 2$ was transiently regulated in the $\mathrm{EC}$, the transcription active mark H3K4me3 showed long-lasting alterations in the EC long after fear learning. These observations are in contrast to previous findings wherein the $\mathrm{H} 3 \mathrm{~K} 9 \mathrm{me} 2$ repressive epigenetic mark in the hippocampus was found to be persistently altered after fear learning (Gupta et al., 2010). Thus, these results are consistent with the idea of regulation of histone methylation in memory and also suggest that HKM is an upstream regulator of chromatin structure in the adult CNS that serves to coordinate both dynamic and persistent gene expression changes in several memory-related brain regions that are critical for LTM formation and storage.

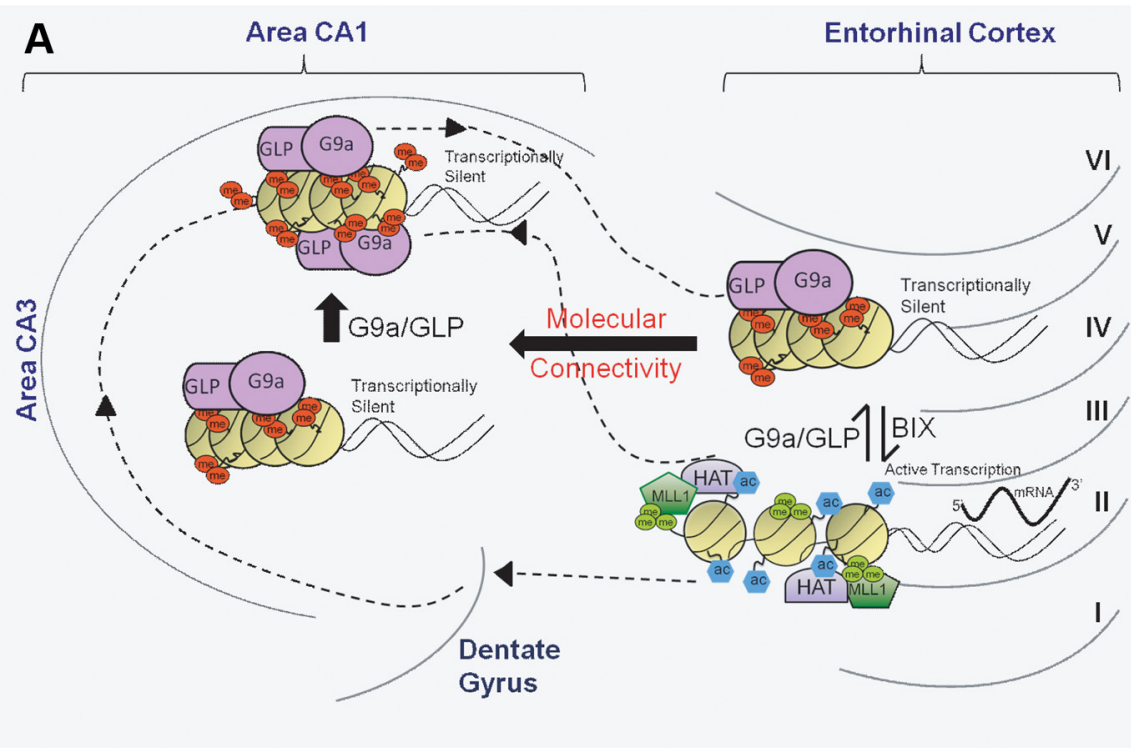

\begin{tabular}{|lc|cc|cc|} 
& \multicolumn{3}{c}{$\begin{array}{c}\text { Area CA1 } \\
\text { Infusion }\end{array}$} & \multicolumn{2}{c|}{$\begin{array}{c}\text { Entorhinal Cortex } \\
\text { Infusion }\end{array}$} \\
\hline Conditions & BIX & Vehicle & BIX & Vehicle \\
\hline Long-term Potentiation & $\downarrow$ & $\uparrow$ & $\uparrow$ & $\uparrow$ \\
\hline Fear Conditioning Behavior & $\downarrow$ & $\uparrow$ & $\uparrow \uparrow$ & $\uparrow$ \\
\hline \multicolumn{4}{|c}{ Memory Consolidation } \\
\hline Gene Expression & CA1 & - & $\downarrow \uparrow$ & $\downarrow \uparrow$ & $\downarrow \uparrow$ \\
& EC & - & - & $\uparrow$ & $\downarrow \uparrow$ \\
\hline H3K9 di-methylation & CA1 & $\downarrow$ & $\uparrow$ & $\uparrow \uparrow$ & $\uparrow$ \\
& EC & $\uparrow$ & $\uparrow$ & $\downarrow$ & $\uparrow$ \\
\hline H3K4 tri-methylation & CA1 & - & $\uparrow$ & $\uparrow$ & $\uparrow$ \\
& EC & $\uparrow \uparrow$ & $\uparrow$ & $\uparrow \uparrow$ & $\uparrow$ \\
\hline H3K9 acetylation & CA1 & - & $\uparrow$ & - & - \\
& EC & - & - & $\uparrow \uparrow$ & $\uparrow$ \\
\hline
\end{tabular}

Figure 7. Model for G9a/GLP transcriptional activity in the hippocampus and EC during memory consolidation. $A$, Model for the ole of $\mathrm{G} 9 \mathrm{a} / \mathrm{GLP}$ in the regulation of chromatin remodeling during long-term memory consolidation. Regulation of histone lysine the hippocampus. The potential role of $\mathrm{G} 9 \mathrm{a} / \mathrm{GLP}$ in cortical-hippocampal molecular connectivity is revealed after infusion of the G9a/GLP inhibitor, BIX01294, in the EC, which alters G9a/GLP-mediated chromatin remodeling homeostasis within the EC and the he consolidation. The changes in chromatin structure in the $\mathrm{EC}$ ultimately results in the enhancement of $\mathrm{H} 3 \mathrm{~K} 9 \mathrm{me} 2 \mathrm{levels}$ and transcriptional gene silencing in the hippocampus that are required for LTM. $\boldsymbol{B}$, Summary table of the major findings from the present study along with previously published studies ( $\left.{ }^{\#}\right)$. The function role of G9a/GLP in the EC and FOS, COMT, and G9a. A single arrow, up or down, indicates comparison with the naive group. A double arrow, up or down, denotes comparison with the vehicle-treated group.

We also observed that inhibition of G9a/GLP in the EC accelerated the rate of memory extinction and that G9a/GLP suppressor activity in the EC, but not the hippocampus, affected amygdala-dependent fear learning. Together, these findings support the role of the EC in LTM extinction and amygdaladependent fear memory formation (Phillips and LeDoux, 1992). These results support manipulation of the G9a/GLP dimethyltransferases as a promising therapeutic avenue for the treatment of fear-related memory disorders in patients suffering from traumatic memories.

Because posttranslational histone modifications can occur in combination with each other in a cell, we examined whether G9a/GLP inhibition in the EC altered $\mathrm{H} 3 \mathrm{~K} 9 \mathrm{me} 2$ regulation as well as other histone modifications in the EC and the hippocampus in response to fear learning. Analysis of G9a/GLP inhibition 
in the EC resulted in the downregulation of the normally observed increases in $\mathrm{H} 3 \mathrm{~K} 9 \mathrm{me} 2$ levels while further elevating $\mathrm{H} 3 \mathrm{~K} 4 \mathrm{me} 3$ and $\mathrm{H} 3 \mathrm{~K}$ 9ac levels in the EC during memory consolidation. Moreover, in the hippocampus, G9a/GLP blockade in the EC further increased H3K9me2 and H3K4me3 regulation. These changes in G9a/GLP-mediated histone modifications were reflected at memory-related gene promoters, such Zif268, $D N M T 3 a$, and BDNF exon $I V$, that correlated with altered mRNA expression within the EC and in the hippocampus. Thus, our findings are consistent with previous research demonstrating a positive correlation between histone acetylation and $\mathrm{H} 3 \mathrm{~K} 4 \mathrm{me} 3$ levels (Zhang et al., 2004) and a negative correlation with H3K9me2 levels (Gupta et al., 2010; Warrener et al., 2010) or G9a genetic knockdown (Plazas-Mayorca et al., 2010). These results underscore the concept that in the CNS, histone modifications do not occur in isolation but, rather, their combinatorial effects mediate the transcriptional signature of genes within brain regions and across brain regions that are necessary for LTM formation. Furthermore, these histone modifications seem to be controlled by G9a/GLP activity in the EC.

This study also suggests that these G9a/GLP-induced histone modifications may not all be required for the transcription of some genes like $c F O S$ since, in BIX01294-treated rats, only H3K4me3 and $\mathrm{H} 3 \mathrm{~K} 9 \mathrm{ac}$ correlate with increased gene expression. Indeed, an unexpected result from our study was that despite the presence of the repressive $\mathrm{H} 3 \mathrm{~K} 9 \mathrm{me} 2$ methylation mark, $c F O S$ mRNA levels further increased in the EC with G9a/GLP blockade. On close examination of the $c F O S$ primers used in our experiments, BLAST genome analysis revealed that our $c F O S$ primer sets amplified exon 4 of the $c F O S$ gene and are in good agreement with previous studies suggesting that $\mathrm{H} 3 \mathrm{~K} 9 \mathrm{me} 2$ enriched at gene coding regions may serve to promote active gene transcription, contrary to its transcriptionally repressive role observed when present at gene promoters (Vakoc et al., 2005). Together, these results provide insights for the role of intragenic methylation regulation, specifically in the form of G9a/GLPmediated $\mathrm{H} 3 \mathrm{~K} 9 \mathrm{me} 2$ activity occurring in the EC during memory consolidation.

Cellular communication between the EC and the hippocampus are critical for relaying sensory information during memory consolidation, as evidenced by synaptic plasticity studies (for review, see Lubin et al., 2011). However, communication in the form of cellular and molecular events exchanged between the EC and the hippocampus at the epigenetic transcriptional level has not been addressed until this study. A novel finding in our study was that G9a/GLP activity in the EC enhanced H3K9me2 levels at the promoter of the nonpermissive COMT gene and decreased COMT mRNA levels in the hippocampus during memory consolidation. Intriguingly, COMT is instrumental for synaptic catabolism of dopamine, and a decrease in COMT activity would result in increased synaptic dopamine levels, which is necessary for LTM (Barnett et al., 2009).

Overall, these studies are exciting because they suggest for the first time that HKM may mediate cellular connectivity between brain regions (i.e., entorhinal cortex and hippocampus) during memory consolidation. Indeed, Ramon y Cajal (1995) observed massive connections between the EC and the hippocampus, leading to the now widely accepted concept of parallel input/output cellular connectivity shared between these two brain regions (Canto et al., 2008; Ahmed and Mehta, 2009). However, the molecular mechanisms necessary for cellular communication between the EC and hippocampus are uncertain. In this regard, our study indicates for the first time a potential role for G9a/GLPmediated HKM regulation in the CNS that may underlie EC- hippocampus cellular connectivity in the adult nervous system during LTM formation. In support of this idea, we show that G9a/GLP activity in the EC differentially regulates $\mathrm{H} 3 \mathrm{~K} 9 \mathrm{me} 2$ within both the EC and the hippocampus to ultimately enhance LTM formation. Hence, this study suggests a fascinating epigenetic mechanism mediating parallel reciprocal molecular connectivity between the EC and the hippocampus during memory consolidation, which we will further investigate in future studies.

Investigation of the role of G9a/GLP activity in mediating molecular connectivity between the EC and the hippocampus prompted additional studies at the cellular level. L-LTP is hypothesized to be the cellular correlate of LTM formation (for review, see Lubin et al., 2011). In addition, cortical contributions, such as the EC to the hippocampus via the TA pathway, have been shown to influence hippocampal output and synaptic plasticity by directly affecting SC-CA1 spike probability (Remondes and Schuman, 2002, 2004). Thus, at the cellular level, we found that G9a/GLP inhibition resulted in normal L-LTP at the TA-CA1 synapse. These results can be interpreted in one of two ways. One possible interpretation is that G9a/GLP activity is not critical to the regulation of synaptic plasticity at the TA-CA1 synapse and instead may function at other cortical-hippocampal cellular connections, such as the perforant pathway. Another possible interpretation is that the L-LTP-induction protocol used in these experiments resulted in maximal activation of the TA-CA1 synapse, causing a ceiling effect, and hence could not be further potentiated in the presence of G9a/GLP activity blockade. Regardless of which interpretation is correct, this study provides a plausible mechanism underlying the enhancement in LTM formation observed with inhibition of G9a/GLP activity in the EC during memory consolidation.

In contrast to TA-CA1 synaptic plasticity, G9a/GLP inhibition attenuated L-LTP at the SC-CA1 synapse, which is consistent with our behavioral findings of an attenuation of LTM formation with G9a/GLP inhibition in area CA1 of the hippocampus. The L-LTP studies performed at the TA-CA1 and the SC-CA1 synapses further our understanding of the differential role of HKM-dependent chromatin restructuring on synaptic plasticity in brain regions. Furthermore, these studies provide insight into whether HKM activity in the $\mathrm{EC}$ and the hippocampus during fear memory consolidation are a consequence or cause of synaptic plasticity underlying the process of LTM formation.

Finally, our results summarized in Figure 7 suggest that more than absolute values, it is the balance between G9a/GLPmediated transcriptional gene activation and silencing in the EC that is critical for normal LTM formation. Moreover, we provide mechanistic insights into how G9a/GLP activity in the EC mediates epigenetic and transcriptional plasticity within both the EC and hippocampus during LTM formation. Our studies also suggest that G9a/GLP activity is critical for synaptic plasticity occurring within the hippocampus. In conclusion, our study is the first to implicate G9a/GLP epigenetic suppressor activity occurring across multiple brain regions recruited during the formation of a memory trace.

\section{References}

Ahmed OJ, Mehta MR (2009) The hippocampal rate code: anatomy, physiology and theory. Trends Neurosci 32:329-338.

Akbarian S, Huang HS (2009) Epigenetic regulation in human brain-focus on histone lysine methylation. Biol Psychiatry 65:198-203.

Barnett JH, Heron J, Goldman D, Jones PB, Xu K (2009) Effects of catecholO-methyltransferase on normal variation in the cognitive function of children. Am J Psychiatry 166:909-916. 
Canto CB, Wouterlood FG, Witter MP (2008) What does the anatomical organization of the entorhinal cortex tell us? Neural Plast 2008:381243.

Cobb SR, Bulters DO, Davies CH (2000) Coincident activation of mGluRs and $\mathrm{mAChRs}$ imposes theta frequency patterning on synchronised network activity in the hippocampal CA3 region. Neuropharmacology 39:1933-1942.

Colombo PJ (2004) Learning-induced activation of transcription factors among multiple memory systems. Neurobiol Learn Mem 82:268-277.

Covington HE 3rd, Maze I, Sun H, Bomze HM, DeMaio KD, Wu EY, Dietz DM, Lobo MK, Ghose S, Mouzon E, Neve RL, Tamminga CA, Nestler EJ (2011) A role for repressive histone methylation in cocaine-induced vulnerability to stress. Neuron 71:656-670.

de la Fuente V, Freudenthal R, Romano A (2011) Reconsolidation or extinction: transcription factor switch in the determination of memory course after retrieval. J Neurosci 31:5562-5573.

De Santa F, Narang V, Yap ZH, Tusi BK, Burgold T, Austenaa L, Bucci G, Caganova M, Notarbartolo S, Casola S, Testa G, Sung WK, Wei CL, Natoli G (2009) Jmjd3 contributes to the control of gene expression in LPSactivated macrophages. EMBO J 28:3341-3352.

Dobrunz LE, Stevens CF (1997) Heterogeneity of release probability, facilitation, and depletion at central synapses. Neuron 18:995-1008.

Fanselow MS (2000) Contextual fear, gestalt memories, and the hippocampus. Behav Brain Res 110:73-81.

Feng J, Zhou Y, Campbell SL, Le T, Li E, Sweatt JD, Silva AJ, Fan G (2010) Dnmt1 and Dnmt3a maintain DNA methylation and regulate synaptic function in adult forebrain neurons. Nat Neurosci 13:423-430.

Fischer A, Sananbenesi F, Wang X, Dobbin M, Tsai LH (2007) Recovery of learning and memory is associated with chromatin remodelling. Nature 447:178-182.

Franklin TB, Mansuy IM (2011) The involvement of epigenetic defects in mental retardation. Neurobiol Learn Mem 96:61-67.

Guan JS, Haggarty SJ, Giacometti E, Dannenberg JH, Joseph N, Gao J, Nieland TJ, Zhou Y, Wang X, Mazitschek R, Bradner JE, DePinho RA, Jaenisch R, Tsai LH (2009) HDAC2 negatively regulates memory formation and synaptic plasticity. Nature 459:55-60.

Gupta S, Kim SY, Artis S, Molfese DL, Schumacher A, Sweatt JD, Paylor RE, Lubin FD (2010) Histone methylation regulates memory formation. J Neurosci 30:3589-3599.

Haettig J, Stefanko DP, Multani ML, Figueroa DX, McQuown SC, Wood MA (2011) HDAC inhibition modulates hippocampus-dependent long-term memory for object location in a CBP-dependent manner. Learn Mem 18:71-79.

Hawk JD, Florian C, Abel T (2011) Post-training intrahippocampal inhibition of class I histone deacetylases enhances long-term object-location memory. Learn Mem 18:367-370.

Knapska E, Kaczmarek L (2004) A gene for neuronal plasticity in the mammalian brain: Zif268/Egr-1/NGFI-A/Krox-24/TIS8/ZENK? Prog Neurobiol 74:183-211.

Korzus E, Rosenfeld MG, Mayford M (2004) CBP histone acetyltransferase activity is a critical component of memory consolidation. Neuron 42:961-972.

Koshibu K, Gräff J, Beullens M, Heitz FD, Berchtold D, Russig H, Farinelli M, Bollen M, Mansuy IM (2009) Protein phosphatase 1 regulates the histone code for long-term memory. J Neurosci 29:13079-13089.

Kubicek S, O'Sullivan RJ, August EM, Hickey ER, Zhang Q, Teodoro ML, Rea S, Mechtler K, Kowalski JA, Homon CA, Kelly TA, Jenuwein T (2007) Reversal of H3K9me2 by a small-molecule inhibitor for the G9a histone methyltransferase. Mol Cell 25:473-481.

LaPlant Q, Vialou V, Covington HE 3rd, Dumitriu D, Feng J, Warren BL, Maze I, Dietz DM, Watts EL, Iñiguez SD, Koo JW, Mouzon E, Renthal W, Hollis F, Wang H, Noonan MA, Ren Y, Eisch AJ, Bolaños CA, Kabbaj M, et al. (2010) Dnmt3a regulates emotional behavior and spine plasticity in the nucleus accumbens. Nat Neurosci 13:1137-1143.

Lee JS, Smith E, Shilatifard A (2010) The language of histone crosstalk. Cell 142:682-685.

Levenson JM, O’Riordan KJ, Brown KD, Trinh MA, Molfese DL, Sweatt JD (2004) Regulation of histone acetylation during memory formation in the hippocampus. J Biol Chem 279:40545-40559.

Levenson JM, Roth TL, Lubin FD, Miller CA, Huang IC, Desai P, Malone LM, Sweatt JD (2006) Evidence that DNA (cytosine-5) methyltransferase regulates synaptic plasticity in the hippocampus. J Biol Chem 281:15763-15773.

Liu F, Chen X, Allali-Hassani A, Quinn AM, Wigle TJ, Wasney GA, Dong A,
Senisterra G, Chau I, Siarheyeva A, Norris JL, Kireev DB, Jadhav A, Herold JM, Janzen WP, Arrowsmith CH, Frye SV, Brown PJ, Simeonov A, Vedadi M, et al. (2010) Protein lysine methyltransferase G9a inhibitors: design, synthesis, and structure activity relationships of 2,4-diamino-7aminoalkoxy-quinazolines. J Med Chem 53:5844-5857.

Lonergan ME, Gafford GM, Jarome TJ, Helmstetter FJ (2010) Timedependent expression of Arc and zif268 after acquisition of fear conditioning. Neural Plast 2010:139891.

Lubin FD, Sweatt JD (2007) The IkappaB kinase regulates chromatin structure during reconsolidation of conditioned fear memories. Neuron 55:942-957.

Lubin FD, Roth TL, Sweatt JD (2008) Epigenetic regulation of BDNF gene transcription in the consolidation of fear memory. J Neurosci 28:10576-10586.

Lubin FD, Gupta S, Parrish RR, Grissom NM, Davis RL (2011) Epigenetic mechanisms: critical contributors to long-term memory formation. Neuroscientist 17:616-632.

Lucio-Eterovic AK, Singh MM, Gardner JE, Veerappan CS, Rice JC, Carpenter PB (2010) Role for the nuclear receptor-binding SET domain protein 1 (NSD1) methyltransferase in coordinating lysine 36 methylation at histone 3 with RNA polymerase II function. Proc Natl Acad Sci U S A 107:16952-16957.

Majak K, Pitkanen A (2004) Do seizures cause irreversible cognitive damage? Evidence from animal studies. Epilepsy Behav 5 [Suppl 1]:S35-S44.

Malvaez M, Mhillaj E, Matheos DP, Palmery M, Wood MA (2011) CBP in the nucleus accumbens regulates cocaine-induced histone acetylation and is critical for cocaine-associated behaviors. J Neurosci 31:16941-16948.

Mansuy IM (2003) Calcineurin in memory and bidirectional plasticity. Biochem Biophys Res Commun 311:1195-1208.

Margueron R, Trojer P, Reinberg D (2005) The key to development: interpreting the histone code? Curr Opin Genet Dev 15:163-176.

Martin C, Zhang Y (2005) The diverse functions of histone lysine methylation. Nat Rev Mol Cell Biol 6:838-849.

Maytal J, Shinnar S, Moshé SL, Alvarez LA (1989) Low morbidity and mortality of status epilepticus in children. Pediatrics 83:323-331.

Maze I, Covington HE 3rd, Dietz DM, LaPlant Q, Renthal W, Russo SJ, Mechanic M, Mouzon E, Neve RL, Haggarty SJ, Ren Y, Sampath SC, Hurd YL, Greengard P, Tarakhovsky A, Schaefer A, Nestler EJ (2010) Essential role of the histone methyltransferase G9a in cocaine-induced plasticity. Science 327:213-216.

McQuown SC, Barrett RM, Matheos DP, Post RJ, Rogge GA, Alenghat T, Mullican SE, Jones S, Rusche JR, Lazar MA, Wood MA (2011) HDAC3 is a critical negative regulator of long-term memory formation. J Neurosci 31:764-774.

Miller CA, Campbell SL, Sweatt JD (2008) DNA methylation and histone acetylation work in concert to regulate memory formation and synaptic plasticity. Neurobiol Learn Mem 89:599-603.

Monsey MS, Ota KT, Akingbade IF, Hong ES, Schafe GE (2011) Epigenetic alterations are critical for fear memory consolidation and synaptic plasticity in the lateral amygdala. PLoS One 6:e19958.

Oliveira AM, Estevez MA, Hawk JD, Grimes S, Brindle PK, Abel T (2011) Subregion-specific p300 conditional knock-out mice exhibit long-term memory impairments. Learn Mem 18:161-169.

Paxinos G, Watson CR, Emson PC (1980) AChE-stained horizontal sections of the rat brain in stereotaxic coordinates. J Neurosci Methods 3:129-149.

Phillips RG, LeDoux JE (1992) Differential contribution of amygdala and hippocampus to cued and contextual fear conditioning. Behav Neurosci 106:274-285.

Pitkanen A, Pikkarainen M, Nurminen N, Ylinen A (2000) Reciprocal connections between the amygdala and the hippocampal formation, perirhinal cortex, and postrhinal cortex in rat. A review. Ann N Y Acad Sci 911:369-391.

Plazas-Mayorca MD, Bloom JS, Zeissler U, Leroy G, Young NL, DiMaggio PA, Krugylak L, Schneider R, Garcia BA (2010) Quantitative proteomics reveals direct and indirect alterations in the histone code following methyltransferase knockdown. Mol Biosyst 6:1719-1729.

Qiu Z (2009) Histone modifier, the gatekeeper of good memory. Cell Res 19:920-921.

Ramón y Cajal S (1995) Histology of the nervous system of man and vertebrates (English translation of Ramón y Cajal Textura del Sistema Nervioso del Hombre y de los Vertebrados by Swanson N, Swanson LW). Oxford, UK: Oxford UP. 
Rea S, Eisenhaber F, O'Carroll D, Strahl BD, Sun ZW, Schmid M, Opravil S, Mechtler K, Ponting CP, Allis CD, Jenuwein T (2000) Regulation of chromatin structure by site-specific histone $\mathrm{H} 3$ methyltransferases. Nature 406:593-599.

Remondes M, Schuman EM (2002) Direct cortical input modulates plasticity and spiking in CA1 pyramidal neurons. Nature 416:736-740.

Remondes M, Schuman EM (2004) Role for a cortical input to hippocampal area CA1 in the consolidation of a long-term memory. Nature 431:699-703.

Schaefer A, Sampath SC, Intrator A, Min A, Gertler TS, Surmeier DJ, Tarakhovsky A, Greengard P (2009) Control of cognition and adaptive behavior by the GLP/G9a epigenetic suppressor complex. Neuron 64:678-691.

Shinkai Y, Tachibana M (2011) H3K9 methyltransferase G9a and the related molecule GLP. Genes Dev 25:781-788.

Sims RJ 3rd, Nishioka K, Reinberg D (2003) Histone lysine methylation: a signature for chromatin function. Trends Genet 19:629-639.

Sun L, Liu SY, Zhou XW, Wang XC, Liu R, Wang Q, Wang JZ (2003) Inhibition of protein phosphatase $2 \mathrm{~A}$ - and protein phosphatase 1-induced tau hyperphosphorylation and impairment of spatial memory retention in rats. Neuroscience 118:1175-1182.

Suganuma T, Workman JL (2008) Crosstalk among histone modifications. Cell 135:604-607.

Tsankova NM, Berton O, Renthal W, Kumar A, Neve RL, Nestler EJ (2006)
Sustained hippocampal chromatin regulation in a mouse model of depression and antidepressant action. Nat Neurosci 9:519-525.

Vakoc CR, Mandat SA, Olenchock BA, Blobel GA (2005) Histone H3 lysine 9 methylation and HP1gamma are associated with transcription elongation through mammalian chromatin. Mol Cell 19:381-391.

Vecsey CG, Hawk JD, Lattal KM, Stein JM, Fabian SA, Attner MA, Cabrera SM, McDonough CB, Brindle PK, Abel T, Wood MA (2007) Histone deacetylase inhibitors enhance memory and synaptic plasticity via CREB:CBPdependent transcriptional activation. J Neurosci 27: 6128-6140.

Vermeulen M, Mulder KW, Denissov S, Pijnappel WW, van Schaik FM, Varier RA, Baltissen MP, Stunnenberg HG, Mann M, Timmers HT (2007) Selective anchoring of TFIID to nucleosomes by trimethylation of histone H3 lysine 4. Cell 131:58-69.

Warrener R, Chia K, Warren WD, Brooks K, Gabrielli B (2010) Inhibition of histone deacetylase 3 produces mitotic defects independent of alterations in histone $\mathrm{H} 3$ lysine 9 acetylation and methylation. Mol Pharmacol 78:384-393.

Yamamoto C (1989) [Memory, learning and glutamate receptor]. Rinsho Shinkeigaku 29:1526-1528.

Zhang K, Siino JS, Jones PR, Yau PM, Bradbury EM (2004) A mass spectrometric "Western blot" to evaluate the correlations between histone methylation and histone acetylation. Proteomics 4:3765-3775. 